\title{
A Wolf in Another Wolf's Clothing: Post-Genomic Regulation Dictates Venom Profiles of Medically-Important Cryptic Kraits in India
}

\author{
Kartik Sunagar $^{1, *}++^{(D}$, Suyog Khochare ${ }^{1,+}$, R. R. Senji Laxme $^{1} \mathbb{D}$, Saurabh Attarde ${ }^{1} \mathbb{D}$, Paulomi Dam ${ }^{1}$, \\ Vivek Suranse $^{1}$ (D), Anil Khaire ${ }^{2}$, Gerard Martin ${ }^{3}$ and Ashok Captain ${ }^{4}$ \\ 1 Evolutionary Venomics Lab, Centre for Ecological Sciences, Indian Institute of Science, \\ Bangalore 560012, Karnataka, India; suyogk@iisc.ac.in (S.K.); senjir@iisc.ac.in (R.R.S.L.); \\ asaurabh@iisc.ac.in (S.A.); paulomidam@iisc.ac.in (P.D.); viveksuranse@iisc.ac.in (V.S.) \\ 2 Indian Herpetological Society, 7/47, Pune Satara Road, Pune 411009, Maharashtra, India; \\ anilkhaire.ihs@gmail.com \\ 3 The Liana Trust, Survey \#1418/1419 Rathnapuri, Hunsur 571189, Karnataka, India; gerry@gerrymartin.in \\ 4 3/1 Boat Club Road, Pune 411001, Maharashtra, India; ashokcaptain@hotmail.com \\ * Correspondence: ksunagar@iisc.ac.in \\ + Equal contribution.
}

check for

updates

Citation: Sunagar, K.; Khochare, S.; Senji Laxme, R.R.; Attarde, S.; Dam, P.; Suranse, V.; Khaire, A.; Martin, G.; Captain, A. A Wolf in Another Wolf's Clothing: Post-Genomic Regulation Dictates Venom Profiles of Medically-Important Cryptic Kraits in India. Toxins 2021, 13, 69. https://doi.org/10.3390/toxins 13010069

Received: 16 December 2020 Accepted: 1 January 2021 Published: 19 January 2021

Publisher's Note: MDPI stays neutral with regard to jurisdictional clai$\mathrm{ms}$ in published maps and institutional affiliations.

Copyright: $(\odot 2021$ by the authors. Licensee MDPI, Basel, Switzerland. This article is an open access article distributed under the terms and conditions of the Creative Commons Attribution (CC BY) license (https:// creativecommons.org/licenses/by/ $4.0 /)$.

\begin{abstract}
The Common Krait (Bungarus caeruleus) shares a distribution range with many other 'phenotypically-similar' kraits across the Indian subcontinent. Despite several reports of fatal envenomings by other Bungarus species, commercial Indian antivenoms are only manufactured against B. caeruleus. It is, therefore, imperative to understand the distribution of genetically distinct lineages of kraits, the compositional differences in their venoms, and the consequent impact of venom variation on the (pre)clinical effectiveness of antivenom therapy. To address this knowledge gap, we conducted phylogenetic and comparative venomics investigations of kraits in Southern and Western India. Phylogenetic reconstructions using mitochondrial markers revealed a new species of krait, Romulus' krait (Bungarus romulusi sp. nov.), in Southern India. Additionally, we found that kraits with 17 mid-body dorsal scale rows in Western India do not represent a subspecies of the Sind Krait (B. sindanus walli) as previously believed, but are genetically very similar to $B$. sindanus in Pakistan. Furthermore, venom proteomics and comparative transcriptomics revealed completely contrasting venom profiles. While the venom gland transcriptomes of all three species were highly similar, venom proteomes and toxicity profiles differed significantly, suggesting the prominent role of post-genomic regulatory mechanisms in shaping the venoms of these cryptic kraits. In vitro venom recognition and in vivo neutralisation experiments revealed a strong negative impact of venom variability on the preclinical performance of commercial antivenoms. While the venom of $B$. caeruleus was neutralised as per the manufacturer's claim, performance against the venoms of B. sindanus and B. romulusi was poor, highlighting the need for regionally-effective antivenoms in India.
\end{abstract}

Keywords: venom evolution; new krait species from India; antivenom therapy; venom proteomics; venom gland transcriptomics; Romulus' krait

\section{Introduction}

The Common Krait (Bungarus caeruleus), one of the 'big four' medically most-important Indian snakes, is well-known for causing numerous fatal envenomings in the country [1,2]. Bites from this nocturnal snake result in neuromuscular paralysis, which is primarily caused by the presence of $\beta$-bungarotoxin in the venom [3]. Considering the near countrywide distribution of this clinically important snake, $B$. caeruleus venoms are used for the manufacture of commercial Indian polyvalent antivenoms. Several reports of fatal envenomings by other superficially similar Bungarus species, which share a distribution range with $B$. caeruleus, have also come to light $[4,5]$. However, their venoms are not used for the 
manufacture of the life-saving antivenom, and the 'big four' antivenom is routinely used for the treatment of envenomings from such neglected species.

The Sind Krait (Bungarus sindanus) with 17 or 19 dorsal scale rows (DSR) at the mid-body, largely shares its geographical distribution with the phenotypically similar B. caeruleus (15 DSR) in Southeastern Pakistan and Western India (Rajasthan, Gujarat and Maharashtra). A subspecies of the Sind Krait-Wall's Sind Krait (B. sindanus walli)—has also been described in the Gangetic Plains of Southeast Asia [6]. Although there have been several anecdotal reports of this subspecies in Western India [7-9] (also considered to be a distinct species, Bungarus walli, by some authors $[10,11])$, its phylogenetic identity remains to be validated.

In this study, by reconstructing species' phylogenetic histories using mitochondrial markers (NADH-ubiquinone oxidoreductase chain 4 (ND4) and cytochrome $b$ (cyt $b$ )), we show that kraits with 17 DSR in Western India do not represent the subspecies B. sindanus walli as previously believed, but are genetically indistinguishable from the Sind krait (B. sindanus) in Pakistan. Additionally, our phylogenetic analyses recovered a new species of krait from Southern India, which we name Romulus' krait (Bungarus romulusi sp. nov.). Through the use of comparative venom proteomics and venom gland transcriptomics, we show that the significant compositional differences in the venoms of cryptic kraits in Southern and Western India likely result from post-genomic regulatory mechanisms. Further, with the help of in vivo experiments in the murine model, we show that the venoms of $B$. sindanus and $B$. romulusi are amongst the most potently toxic snake venoms in the country, being over 11 and 6 times more potent than that of B. caeruleus, respectively. Consistent with previous clinical findings [4], our in vitro venom recognition assays and in vivo venom neutralisation experiments highlight the extremely poor efficacies of commercial antivenoms in treating $B$. sindanus envenomings. Thus, we highlight the importance of molecular phylogenetics in identifying clinically-important cryptic snake species and the pressing need for the development of regionally-effective antivenoms in India to counter the dramatic inter and intraspecific venom variations.

\section{Results}

To unravel the phylogenetic relationships and venom variation in cryptic kraits from Southern and Western India, we sampled scales, venoms, venom glands and physiological tissues from kraits with either 15- or 17-mid-body DSRs (Figure 1; Table S1).

\subsection{Phylogenetic Reconstructions}

Phylogenetic reconstructions of two mitochondrial markers provided fascinating insights into the evolution of kraits in the Indian subcontinent (Figure 2 and Figures S1-S3). The overall topology of Bungarus phylogeny was in complete agreement with the previously reported multilocus species tree [12]. Consistent with the literature, $B$. sindanus was recovered as a sister lineage to B. caeruleus (Bayesian Posterior Probability (BPP): 1; bootstrap (BS): 95). Interestingly, sequences from the 17-mid-body scale row krait from Maharashtra were found in the same clade as B. sindanus from Pakistan (BPP: 1; BS: 100). Surprisingly, however, B. caeruleus was found to be polyphyletic with four distinct clades (Figure 2 and Figures S1-S3). The 15 DSR krait from Karnataka was found in a distinct clade to its counterparts from West Bengal and Maharashtra (BPP: 1; BS: 100). In contrast, the 15 DSR krait from Maharashtra was recovered as a sister lineage to B. caeruleus from Pakistan (BPP: 0.85; BS: 66). This clearly suggests that the 15 DSR krait from Karnataka is likely to be a genetically distinct species. 


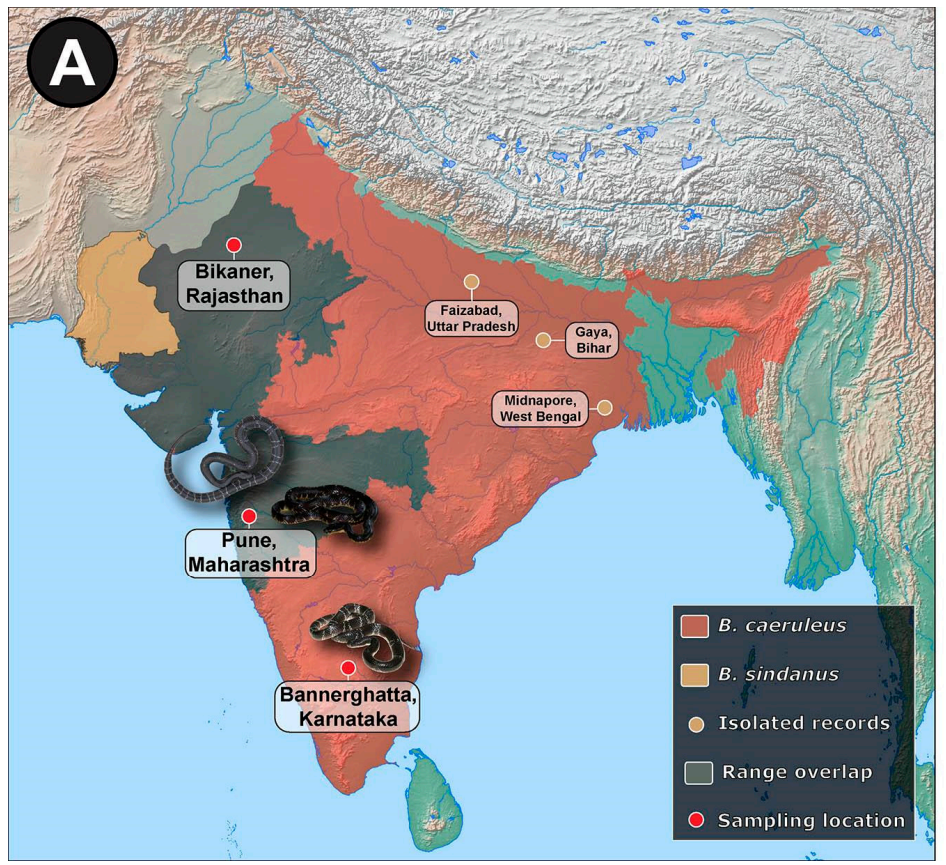

\section{B SDS-PAGE}

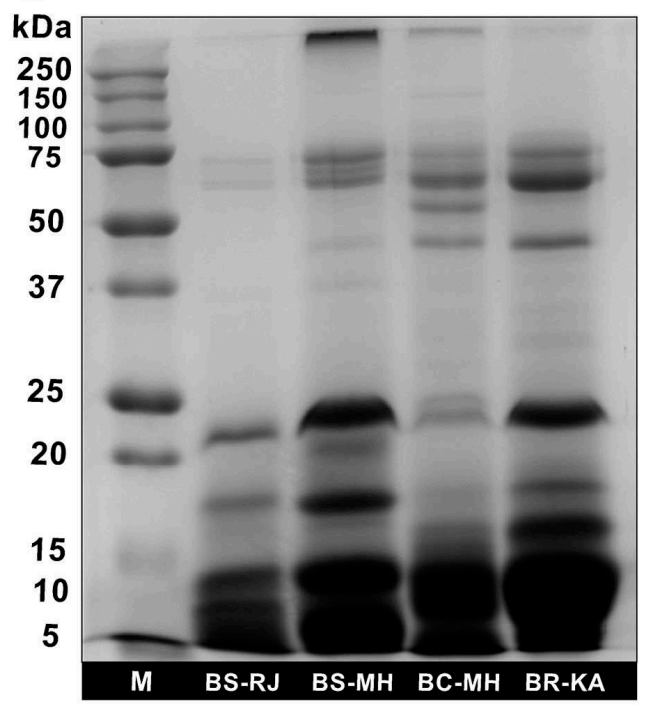

Figure 1. The range distribution of Bungarus spp. in Southern and Western India and SDS-PAGE profiles of their venoms. (A). Panel A of this figure shows the range distribution of B. sindanus (light brown) and B. caeruleus (red), and their range overlaps (grey) in the Indian subcontinent. Isolated records of B. sindanus (light brown circles), along with sampling locations (red circles) of venoms and venom glands have also been shown. (B). SDS-PAGE profiles of venom samples [B. sindanus (Rajasthan and Maharashtra), B. caeruleus (Maharashtra) and B. romulusi (Karnataka)], along with the marker $(\mathrm{M})$, are shown in panel B.

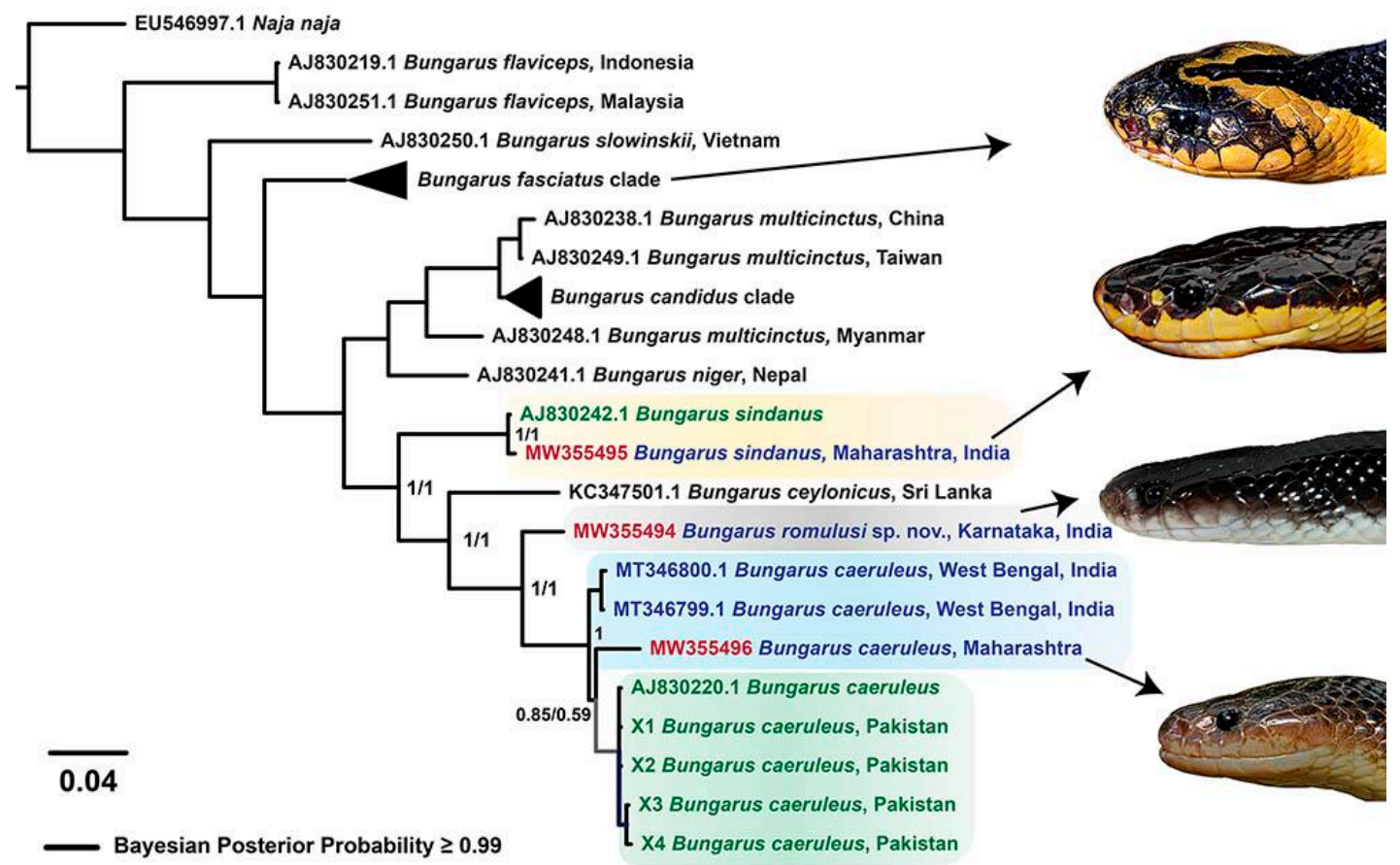

Figure 2. Bayesian phylogeny of Bungarus species. This figure highlights the phylogenetic relationships between Bungarus species in Asia. Distinct lineages of kraits of interest have been shown in uniquely coloured boxes. Branches with superior node support (BPP $\geq 0.95)$ are shown in thick black lines, and the BPP values for ND4 and cyt $b$ markers are indicated for the clades of interest. Branch lengths in the tree are scaled by the number of nucleotide substitutions per site. Photographs depicting the lateral view of B. fasciatus, B. sindanus, B. romulusi and B. caeruleus have also been shown. 
The estimation of evolutionary divergence between the mitochondrial sequences (ND4 and cyt $b$ ) strongly supported the aforementioned findings (Tables S2-S5). Minor pairwise differences were noted between ND4 and cyt $b$ sequences of the 17 DSR krait from Maharashtra and the B. sindanus from Pakistan $(0.32 \%$ and $3.03 \%$, respectively). This clearly shows that kraits with 17 DSR at mid-body in Western India are very closely related to $B$. sindanus, and assigning them to a subspecies (B. sindanus walli) or distinct species (B. walli) is questionable. Similarly, very few pairwise differences in nucleotides were documented between the 15 DSR krait from Maharashtra and its B. caeruleus counterparts from West Bengal (ND4: 2.69\% to 3.25\%). While the divergence between the ND4 and some of the cyt $b$ sequences of the 15 DSR krait from Maharashtra and B. caeruleus from Pakistan were minimal (ND4: $2.35 \%$ to $3.73 \%$ and cyt $b$ : $3.69 \%$ to $3.93 \%$ ), cyt $b$ sequence divergence between certain individuals were considerably large (5.61\% to 6.55\%). In complete contrast, significant differences were observed in the mitochondrial sequences of the 15 DSR krait from Karnataka, in comparison to its counterparts in Maharashtra (ND4: $8.6 \%$ and cyt $b$ : $14.2 \%$ ) and West Bengal (ND4: $6.96 \%$ to $7.09 \%$ ). Considerable differences were also observed when these sequences from the Karnataka specimen with 15 DSR were compared with B. caeruleus from Pakistan (ND4: $7.72 \%$ to $8.30 \%$ and cyt $b: 6.67 \%$ to $12.04 \%$ ). This conclusively shows that the 15 DSR krait from Karnataka represents an unrecognised species. For his remarkable contribution to the field of herpetology, we name this new krait species as Romulus' krait (Bungarus romulusi sp. nov.) in honour of Indian herpetologist, Romulus Whitaker.

\subsection{Venom Proteomics}

SDS-PAGE profiling of B. sindanus (Rajasthan and Maharashtra), B. caeruleus and $B$. romulusi venoms revealed considerable qualitative and quantitative differences. While the venoms of all three species were dominated by low-molecular-weight toxins $(<10 \mathrm{kDa})$, major differences in intermediate- $(20-50 \mathrm{kDa})$ and high-molecular-weight ( $>50 \mathrm{kDa})$ toxins were also noted (Figure 1B). Barring the minor intraspecific differences in intensities and banding patterns of the venoms of $B$. sindanus from Rajasthan and Maharashtra, distinct SDS-PAGE profiles were observed for the three species. To precisely identify the compositional differences, we subjected whole venoms to tandem mass spectrometry. Searching the generated spectra against NCBI-NR Serpentes database and the Bungarus transcriptomes generated in this study led to the identification of 147, 225 and 132 non-redundant toxin proteins in the venoms of $B$. sindanus, $B$. caeruleus and $B$. romulusi, respectively (Figure 3A; Tables S6-S8). The identified toxins belonged to 19 families, namely threefinger toxin (3FTx), phospholipase $\mathrm{A}_{2}\left(\mathrm{PLA}_{2}\right), \beta$-bungarotoxin, cobra venom factor $(\mathrm{CVF})$, cysteine-rich secretory proteins (CRISP), 5'-nucleotidase, disintegrin-like toxins, C-type lectin (CTL), L-amino-acid oxidase (LAAO), nerve growth factor (NGF), Kunitz-type serine protease inhibitor (Kunitz), vespryn, acetylcholinesterase (AChE), phospholipase B (PLB), snake venom serine protease (SVSP), vascular endothelial growth factor (VEGF), phosphodiesterases (PDE), hyaluronidase (HYL), and peptidase S1 (Figure 3A; Tables S6-S8). 


\section{A Venom Proteome}
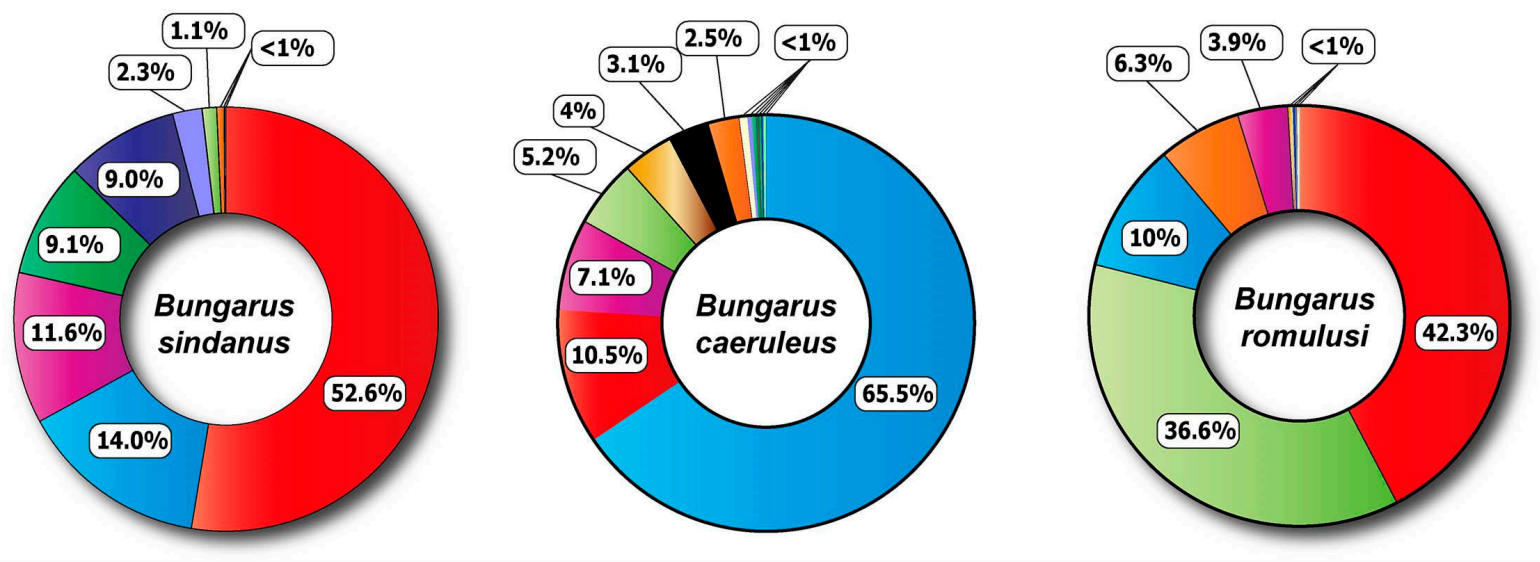

\section{B \\ Venom Gland Transcriptome}

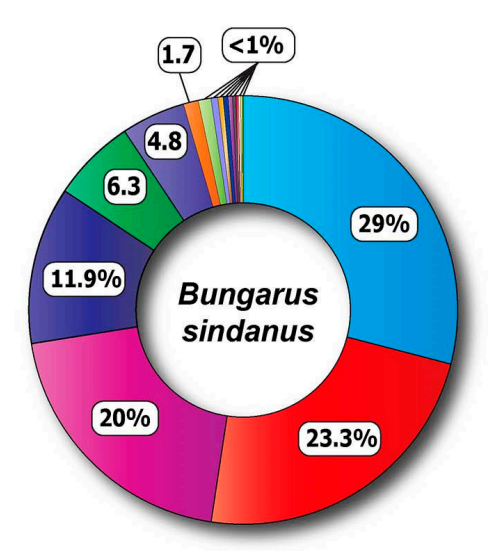

3FTx

CRISP

Hyaluronidase

PDE

VEGF

CTL

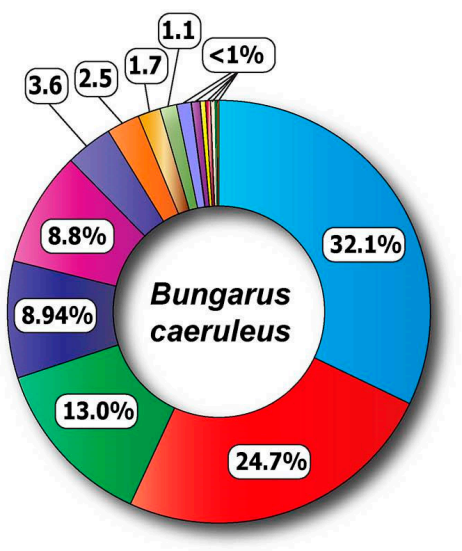

B-bungarotoxin $\square \mathrm{AChE}$

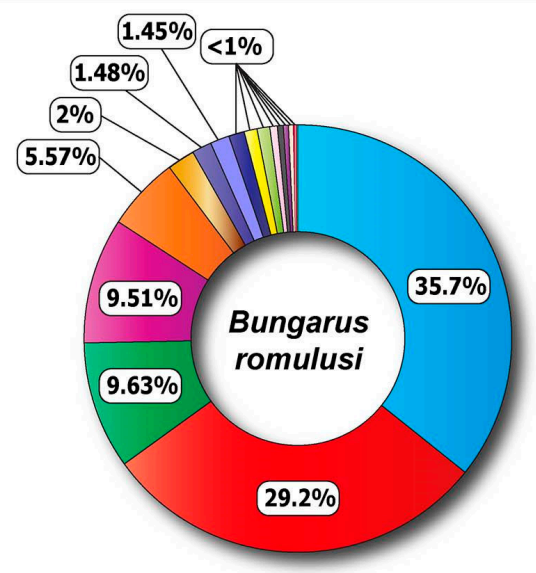

Calreticulin

5'-nucleotidase

CVF

Disintegrin-like

DPP

LAAO

$\mathrm{PLA}_{2}$
Natriuretic peptide

PLB
NGF

Serine Protease

Figure 3. The comparative venom proteomic and venom gland transcriptomic profiles of B. sindanus, B. caeruleus and B. romulusi. Here, doughnut charts depict the relative abundance of various toxins in (A) the venom proteome and (B) the venom gland transcriptomes of the three cryptic kraits. Individual toxins are uniquely colour coded, and their relative abundances are indicated in percentages.

Mass spectrometry of the venoms of the three krait species revealed significant differences in proportions of neurotoxic 3FTxs and $\mathrm{PLA}_{2} \mathrm{~s}$. While the venom proteome of B. caeruleus was enriched with various subtypes of neurotoxic 3FTxs (65\%), surprisingly, only a smaller fraction of $B$. sindanus (14\%) and B. romulusi $(10 \%)$ venom proteomes were constituted by them (Figure 3A). In contrast, nearly $53 \%$ of the B. sindanus and $42 \%$ of $B$. romulusi venoms were made up of $\mathrm{PLA}_{2}$ toxins, whereas less than $11 \%$ of $B$. caeruleus venom contained PLA ${ }_{2}$ s. The relative abundance of $3 \mathrm{FTx}$, followed by $\mathrm{PLA}_{2}$ and $\beta$-bungarotoxin, has also been documented in the venom proteome of a nearby population (Tamil Nadu) of B. caeruleus [13]. While the relative abundance of 3FTx and PLA 2 in B. sindanus (Maharash- 
tra) was also very similar to the abundance of these components in the venom proteomes of B. sindanus from Pakistan [14] and Rajasthan [15], the venom of the former population was more abundant in $\mathrm{PLA}_{2}$ toxins (Figure $3 \mathrm{~A}$ ). Interestingly, nearly $12 \%$ of the $B$. sindanus venom proteome was composed of $\beta$-bungarotoxin: a presynaptic neurotoxin, which is a heterodimer of $\mathrm{PLA}_{2}$ and Kunitz peptides [16], while B. caeruleus and B. romulusi only contained around $7 \%$ and $4 \%$ of this toxin type, respectively. Quantitative proteomics experiments have previously shown that the relative abundance of this toxin type varies significantly between Bungarus species, ranging from nearly half of the venom composition in certain South East Asian species to minor amounts (0.6\% to 5\%) documented in the Sri Lankan B. caeruleus [14]. Astonishingly, the venom of the B. romulusi $(37 \%)$ was found to be rich in acetylcholinesterase, while constituting a minor fraction of $B$. caeruleus $(5 \%)$ and $B$. sindanus ( $1 \%)$ venoms. The three species also differed in their abundance of LAAO, CRISP and Kunitz serine protease inhibitors (Figure 3A).

These findings were also supported by the densitometric analyses of SDS-PAGE profiles (Figure 1B and Figure S4A,B). The abundance of AChE (64-78 KDa), CRISP ( 26 KDa), $\beta$-bungarotoxin $(\sim 16 \mathrm{KDa}$ under reducing and $21 \mathrm{KDa}$ under non-reducing conditions: Figure 1B and Figure S4B), PLA 2 (13-15 KDa), Kunitz ( 9 KDa) and 3FTx (7-9 KDa) correlated with the intensities of the bands at the respective molecular weight ranges.

\subsection{Comparative Transcriptomics}

RNA sequencing of $B$. sindanus, B. caeruleus and B. romulusi tissues on Illumina's HiSeq $X$ platform resulted between $24,343,212$ and $51,842,239$ sequences from the venom glands and between 12,058,000 and 55,336,796 sequences from the intestinal tissues (Table S9). De novo comparative transcriptomes assembled with these sequences retrieved $229,763,308,570$ and 225,522 transcripts from B. sindanus, B. caeruleus and B. romulusi, respectively. Annotation of venom gland transcripts, followed by differential expression analyses, revealed the upregulation of multiple toxin-encoding genes in the venom glands in comparison to the intestine (Tables S10-S12). In addition to recovering large numbers of short- (Type I) and long-chain (Type II) $\alpha$-neurotoxins, $\mathrm{k}$-bungarotoxin, unconventional $3 \mathrm{FTxs}, \mathrm{PLA}_{2} \mathrm{~s}$ and $\beta$-bungarotoxin, we identified $5^{\prime}$-nucleotidase, acetylcholinesterase, CRISP, CTL, disintegrin-like SVMPs, hyaluronidase, Kunitz, LAAO, natriuretic peptide, NGF, phospholipase B, VEGF and vespryn as differentially up-regulated in the venom glands in comparison to the physiological tissue (between 2 to $22 \log _{2}$ fold change; probability > 0.9). While the role of this toxin in snakebite pathology remains unknown, dipeptidyl peptidase-4 (DPP-4) sequences were uniquely retrieved from the venom glands of B. caeruleus [17].

In contrast to the stark differences observed in the venom proteomes of the three species, venom gland transcriptomes were fairly similar (Figure 3B). Consistent with the venom gland transcriptomes of the other Asian kraits [18-20], comparative tissue expression analyses in this study revealed the domination of neurotoxic 3FTx and PLA 2 transcripts in the venom glands of all three Bungarus species (Figure 3B). While between 29 to $36 \%$ of all toxin transcripts belonged to the $3 \mathrm{FTx}$ superfamily, $\mathrm{PLA}_{2} \mathrm{~S}$ constituted between $23 \%$ to $29 \%$ of the venom gland toxin transcriptome. $\beta$-bungarotoxin was found equally abundant in B. caeruleus and B. romulusi ( $9 \%)$, whereas $20 \%$ of the venom gland transcriptome of $B$. sindanus consisted of this toxin type. Minor differences were observed in the abundance of CRISPs, disintegrin-like SVMPs, Kunitz, LAAO and natriuretic peptides between the three species. The significant difference documented between the venom proteomes and venom gland transcriptomes, particularly in the abundance of $3 \mathrm{FTx}, \mathrm{PLA}_{2}$ and $\beta$-bungarotoxin, suggests the possible role of post-transcriptional regulatory mechanisms in shaping the venoms of these cryptic kraits. Among the physiological protein-coding genes that were found to be overexpressed in the venom glands of all three species of kraits were those encoding a large number of disulphide isomerase isoforms (2.1-7.1 $\log _{2}$ fold change; probability $>0.9$ ). Specific isoforms of these enzymes, which are essential for the 
proper folding of cysteine-rich proteins, including venom toxins, have also been shown to be overexpressed in the venom producing cells of other venomous animals [21].

\subsection{Coagulopathic Effects of Bungarus Venoms}

While this is not a major pathology documented in Elapidae snake envenoming, in the preclinical setting, the venoms of certain Indian elapids have been shown to affect hemostasis by interfering with the intrinsic and/or extrinsic coagulation cascades [15,22-24]. Therefore, we examined the abilities of Bungarus venoms to affect these pathways via activated partial thromboplastin time (aPTT) and prothrombin time (PT) assays, respectively. While none of the tested venoms affected the extrinsic coagulation cascade, all venoms exhibited significant effects on the intrinsic pathway (Figure S5A,B). In line with the previous findings [15], the venoms of $B$. sindanus and $B$. caeruleus from Maharashtra were found to significantly alter aPTT values (coagulation delayed by 111 and $600 \mathrm{~s}$ at $40 \mu \mathrm{g}$, respectively), whereas $B$. romulusi venom exhibited considerable effects only at very high concentrations (coagulation delayed by $73 \mathrm{~s}$ at $40 \mu \mathrm{g}$ ). Similarly, in the haemolytic assays, B. caeruleus exhibited maximal activity in comparison to the $0.5 \%$ Triton X-100 positive control $(29 \%)$, closely followed by $B$. sindanus (16\%), whereas B. romulusi showed minimal haemolytic effects (8\%) (Figure S5C).

\subsection{In Vitro Venom Recognition Potential of Commercial Antivenoms}

We performed enzyme-linked immunosorbent assay (ELISA) and immunoblotting in vitro experiments to measure the potential of commercial Indian polyvalent antivenoms (Premium Serums and Vaccines Pvt. Ltd. (PSVPL), Pune, India and Haffkine BioPharmaceutical Corporation Ltd. (Haffkine), Mumbai, India) in recognising the venoms of the three krait species (Figure 4; Table S13). While both antivenoms recognised the venoms of B. caeruleus (titre: 1:500; PSVPL: 1.02 Optical Density (OD); Haffkine: 0.89 OD) and $B$. sindanus (titre: 1:500; PSVPL: 0.89 OD; Haffkine: 0.76 OD) relatively well, they exhibited limited to poor recognition potential against the venom of $B$. romulusi (titre: 1:500; PSVPL: 0.24 OD; Haffkine: 0.25 OD) (Figure 4). These results are indicative of the poor preclinical effectiveness of Indian antivenoms against $B$. romulusi.

Immunoblotting experiments revealed that the commercial antivenoms very poorly recognised the highly abundant low-molecular-weight toxins $(<20 \mathrm{KDa})$ in Bungarus venoms (Figure 5 and Figure S6). While Premium serums antivenom exhibited relatively increased binding towards the B. caeruleus venom in comparison to the venoms of B. romulusi and the two populations of $B$. sindanus, the Haffkine antivenom failed to recognise several toxins from all Bungarus species tested in the study (Figure 5 and Figure S6). As the Haffkine antivenoms are manufactured by sourcing venoms from the state of Maharashtra in Western India, the poor venom recognition of this antivenom against the source venom immunogen population is surprising. Moreover, non-specific binding of naive horse Immunoglobulins $\mathrm{G}$ (IgGs) towards certain toxin bands was also observed.

\subsection{Toxicity Profiles}

Evaluation of toxicity profiles (or the median lethal dose $\left(\mathrm{LD}_{50}\right)$ ) of Bungarus species in the mouse model revealed dramatic differences in venom potencies. While the toxicity of $B$. caeruleus, the most potent of the 'big four' Indian snakes, was in line with previous findings $(0.25 \mathrm{mg} / \mathrm{kg}$; [15]), the newly discovered B. romulusi exhibited six times more toxicity $(0.045 \mathrm{mg} / \mathrm{kg})$. Moreover, B. sindanus (the 17 DSR krait from Maharashtra) was found to be amongst the most toxic snakes identified in India. Consistent with the toxicity score reported for the Rajasthani population of this species $(0.018 \mathrm{mg} / \mathrm{kg}$; [15]), B. sindanus from Maharashtra was characterised with an $\mathrm{LD}_{50}$ of $0.02 \mathrm{mg} / \mathrm{kg}$ (Figure 6A, Table S14). 


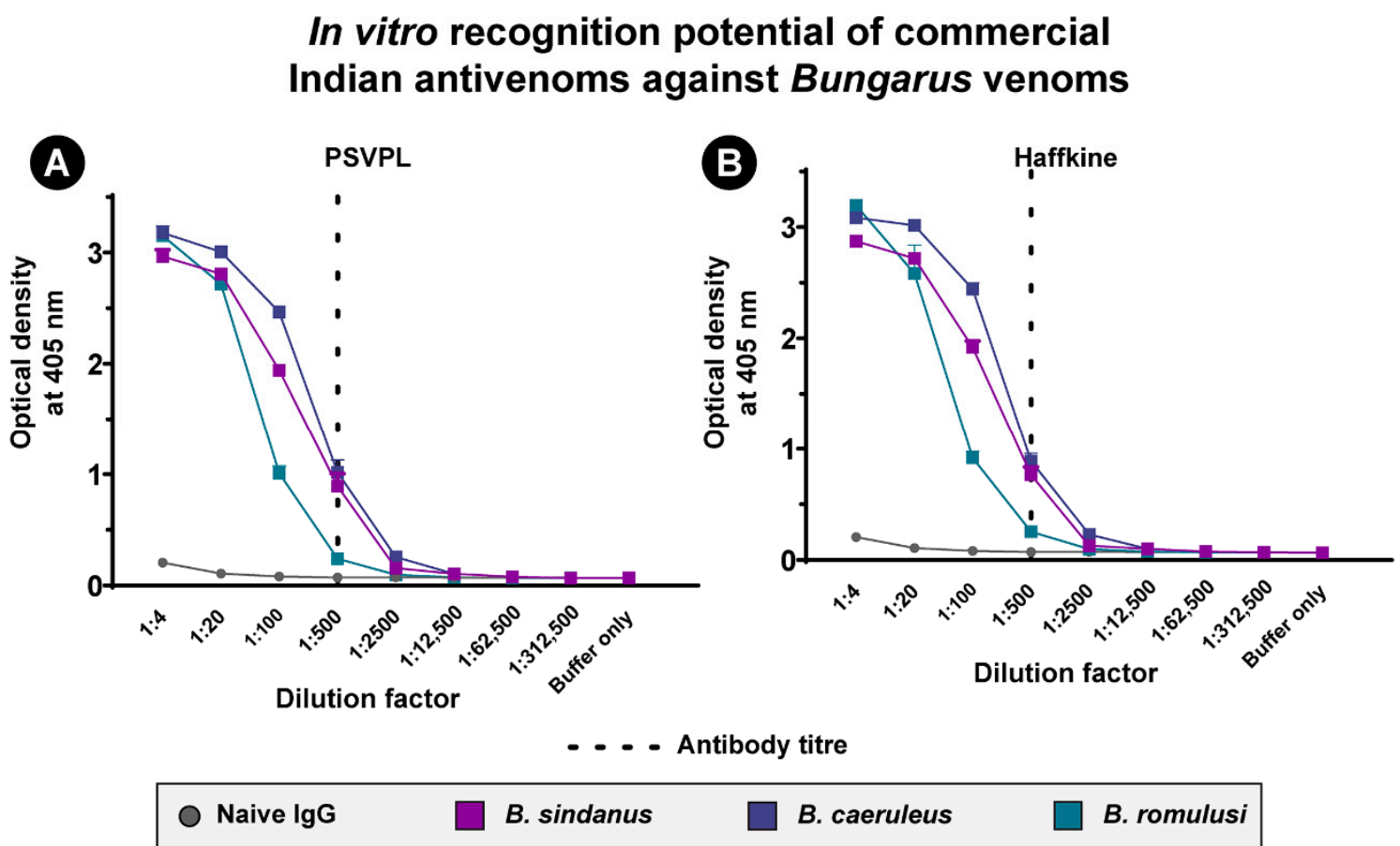

Figure 4. The in vitro recognition potential of commercial Indian antivenoms against Bungarus venoms. The venom recognition potential of naive horse Immunoglobulins G (IgG) and commercial Indian antivenoms (A) PSVPL and (B) Haffkine against the venoms of B. sindanus, B. caeruleus and B. romulusi, determined using end-point ELISA, is shown here. The absorbance values are plotted as mean of triplicates, and the standard deviation is shown in the form of error bars.

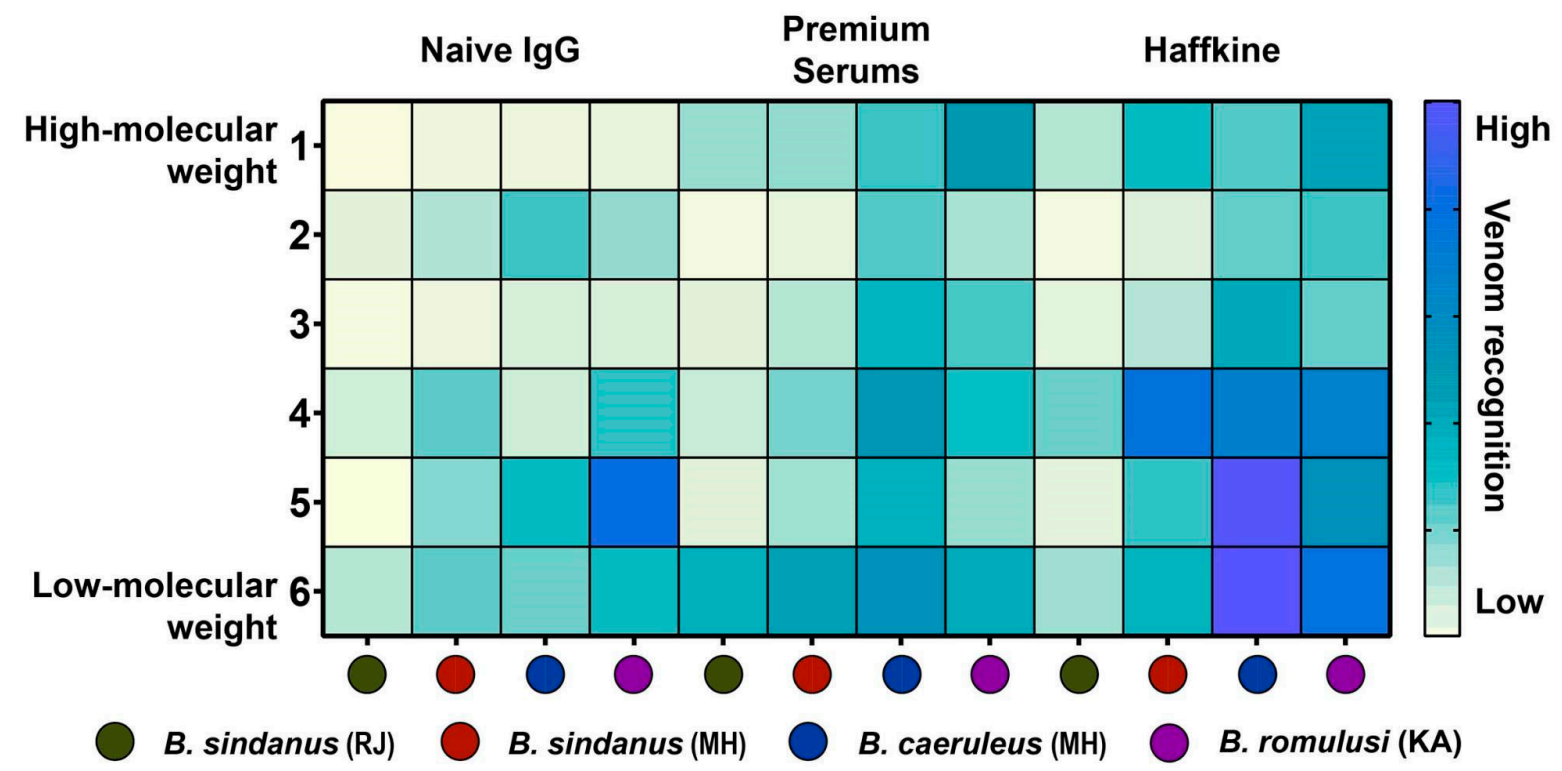

Figure 5. The venom recognition potential of commercial Indian antivenoms and naive horse IgGs against Bungarus venoms, as revealed by Western blotting experiments are depicted here. Densitometric analyses of immunoblot bands (1 to 6) are plotted as a heatmap, and a gradient of yellow to blue colouration indicates low to high venom recognition potential, respectively. 


\section{A Median lethal dose $\left(L_{50}\right)$}

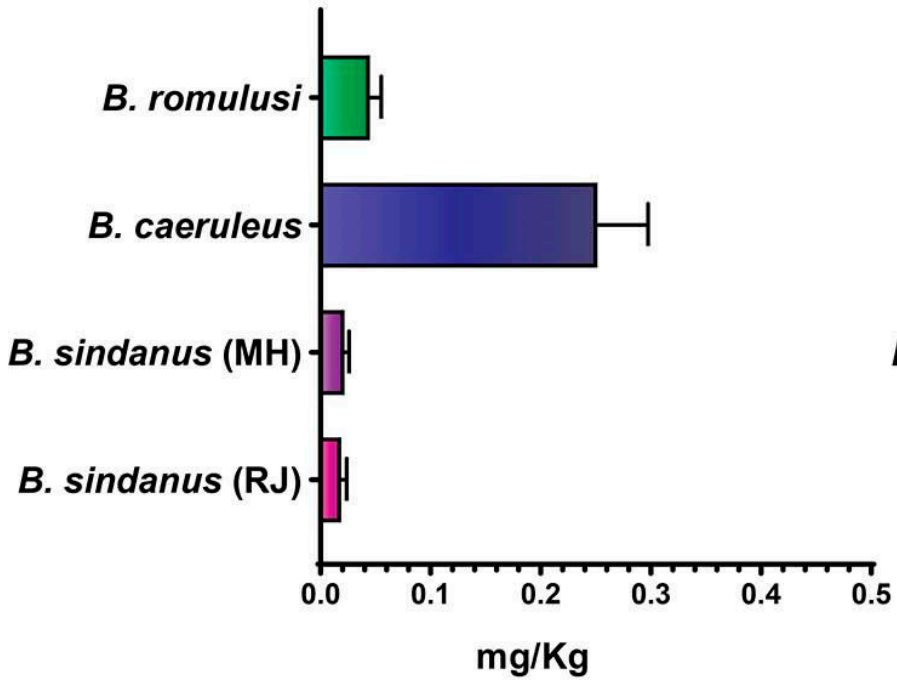

B Neutralisation potency

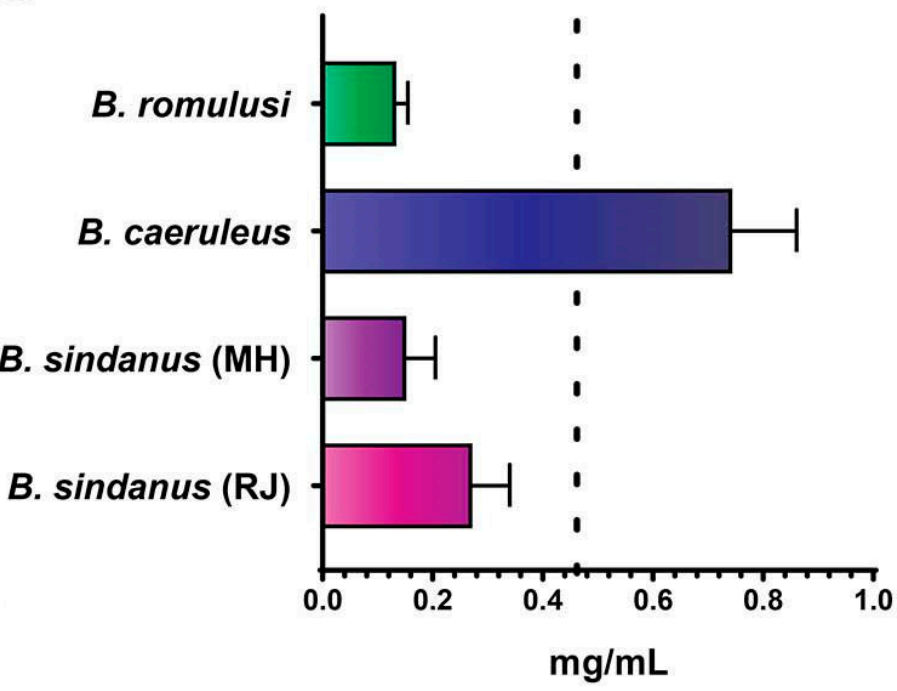

Figure 6. The toxicity profiles of Bungarus venoms and the neutralisation potencies of commercial Indian antivenoms. This figure shows $(\mathbf{A})$ venom potencies $(\mathrm{mg} / \mathrm{Kg})$ of kraits and $(\mathbf{B})$ the neutralisation potency $(\mathrm{mg} / \mathrm{mL})$ of PSVPL antivenom against them. Here, the error bars represent $95 \%$ confidence intervals, while the vertical dotted line in panel B indicates the marketed potency of 'big four' antivenoms against B. caeruleus $(0.45 \mathrm{mg} / \mathrm{mL})$. $\mathrm{LD}_{50}$ of B. sindanus from Rajasthan and the neutralisation potency value against it are from [15].

\subsection{In Vivo Venom Neutralisation}

Consistent with the outcomes of in vitro venom binding assays, in vivo venom neutralisation experiments in the murine model revealed the poor preclinical potencies of commercial antivenoms against $B$. sindanus and B. romulusi. While the tested antivenom (PSVPL) exhibited relatively better performance against $B$. caeruleus from Maharashtra $(0.744 \mathrm{mg} / \mathrm{mL})$ than the marketed value $(0.45 \mathrm{mg} / \mathrm{mL})$, it was characterised with alarmingly inefficient neutralisation potencies against both $B$. sindanus $(0.15 \mathrm{mg} / \mathrm{mL})$ and B. romulusi $(0.13 \mathrm{mg} / \mathrm{mL})$ (Figure $6 \mathrm{~B}$, Table $\mathrm{S} 15)$. This trend remains consistent with previous findings where the commercial polyvalent antivenom manufactured by VINS performed relatively better against the venom of $B$. caeruleus from India $(0.48 \mathrm{mg} / \mathrm{mL}) \mathrm{but}$ performed poorly against $B$. sindanus from Pakistan $(0.25 \mathrm{mg} / \mathrm{mL})[14,25]$. Interestingly, the PSVPL antivenom was previously found to exhibit very poor neutralisation efficacy against the venoms of both $B$. sindanus from Rajasthan $(0.272 \mathrm{mg} / \mathrm{mL})$ and B. caeruleus from Punjab (0.312 mg/mL) [15].

\section{Discussions}

\subsection{Cryptic Kraits of Southern and Western India}

India is an abode to at least seven described species of kraits [7], some of which possess the most potently toxic venoms in the world [15]. To date, kraits with 15, 17 and, very rarely, 19 DSR have been reported in Western India. While kraits with 15 DSR in Peninsular India are identified as $B$. caeruleus, those with 17 or 19 DSR are attributed to either $B$. sindanus or B. sindanus walli (some authors have also called the latter B. walli), depending on their geographical distribution. Kraits with 17 DSR in India that are geographically closer to the Sind region of Pakistan are believed to be $B$. sindanus, whereas isolated records of kraits with 17 or 19 DSR in the other parts of the country have been called B. sindanus walli or $B$. walli, without any scientific evidence. In fact, Wall's krait (B. walli) was originally described by a British herpetologist, Frank Wall, from the princely State of Oudh, Faizabad [10], which was later synonymised with the Sind krait (B. sindanus) and then assigned a subspecies status (B. sindanus walli) by Khan [6]. Given their phenotypic similarity 
(Figure 7), it can be challenging for clinicians and laypeople to distinguish them from one another.
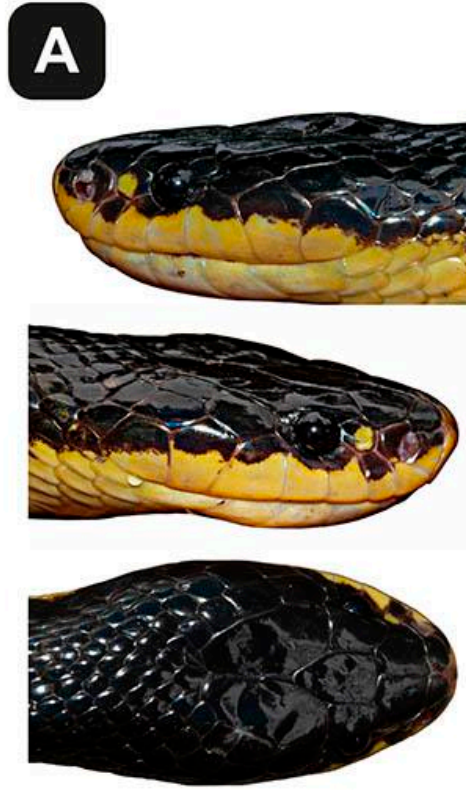

\section{D}

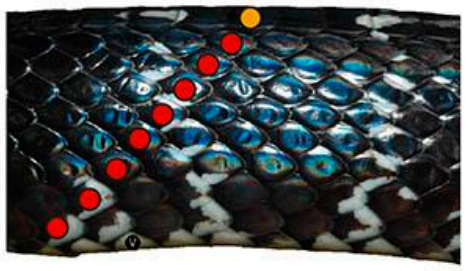

\section{B}
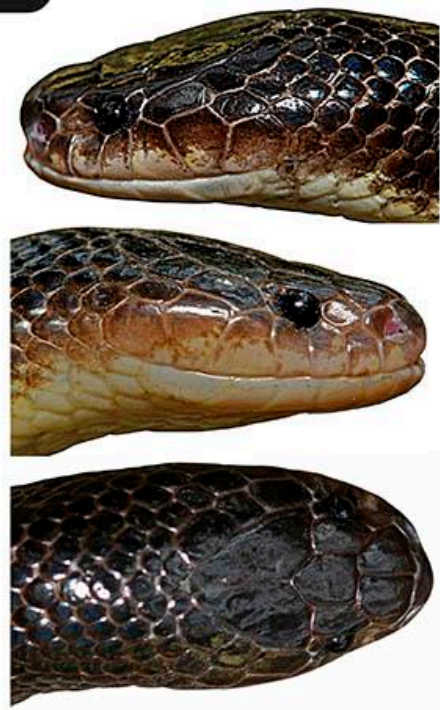

E

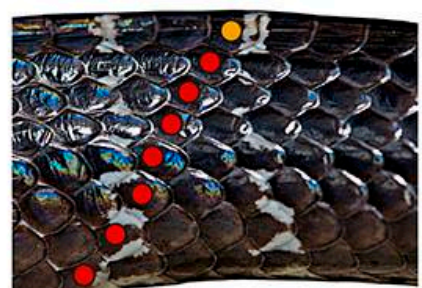

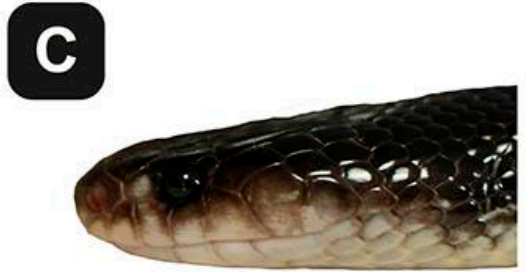
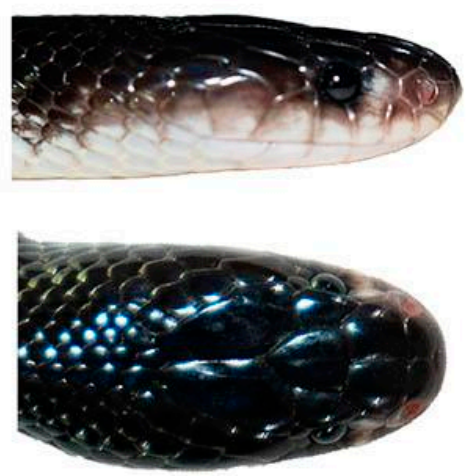

F

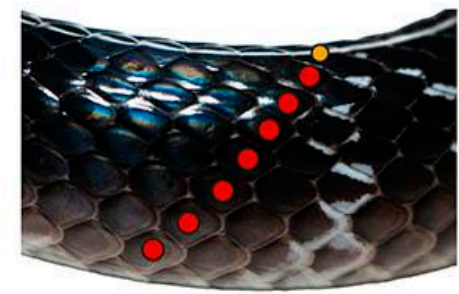

Figure 7. Phenotypic similarities and differences in the cryptic kraits of Southern and Western India. These photographs highlight the morphological differences between (A) B. sindanus, (B) B. caeruleus and (C) B. romulusi. The images in the panels (D-F) show the lateral view of the mid-body, highlighting the edges of the ventral scales, the adjacent dorsal scale rows (7 or 8 red dots) and the uppermost dorsal scale row (yellow dot). The corresponding scale rows on the other side are not visible, and the total mid-body dorsal scale count (i.e., 17 in B. sindanus and 15 in B. caeruleus and B. romulusi) is by inference. Full-body images of B. romulusi have also been deposited in MorphoBank (\#3897).

Phylogenetic reconstructions using cytochrome $b$ and ND4 mitochondrial markers in this study revealed fascinating insights into the evolution of cryptic kraits in Southern and Western India. Consistent with previously unpublished suggestions [4], our analyses did not recover any support for describing the 17 mid-body DSR kraits in Western India as a subspecies of $B$. sindanus (i.e., B. sindanus walli), or a completely distinct species (B. walli), but rather unravelled the limited molecular divergence of this population in comparison to B. sindanus in Pakistan $(0.32 \%$ and $3.03 \%$ for ND4 and cyt $b$ markers, respectively; Tables S2-S5). Considering this compelling molecular evidence, we suggest renaming the 17 DSR kraits in Western India to $B$. sindanus.

Fascinatingly, phylogenetic analyses revealed that the 15 DSR krait lineage is highly polyphyletic, with the Karnataka population forming a completely distinct clade (BPP of 1 for cyt $b$ and ND4). Considering the very high molecular divergence of this clade from the other 15 DSR kraits (6.6\% to $13.21 \%$ and $6.96 \%$ to $8.61 \%$ for cyt $b$ and ND4 markers, respectively), we name this lineage as $B$. romulusi in the honour of the famous Indian herpetologist, Romulus Whitaker. While we did not document significant morphological 
differences between B. caeruleus and B. romulusi, with the exception of the colour, which by itself is an unreliable character, we had access to a limited number of samples due to restrictions in our permissions from the authorities. The description of this species is, therefore, based on the overwhelming support drawn from phylogenetic reconstructions, sequence divergence estimates, venom proteomes, and toxicity profiles. Interestingly, while a minimal sequence divergence was observed in the ND4 and many cyt $b$ sequences of the 15 DSR kraits in Maharashtra, Orissa (cyt $b: 3.42$ ) and B. caeruleus in Pakistan (ND4: $2.35 \%$ to $3.73 \%$ and cyt $b: 3.69 \%$ to $3.93 \%$ ), larger differences were also observed in the cyt $b$ region of the other individuals (5.61\% to $6.55 \%$ ). The significant divergence observed in the cyt $b$ marker, perhaps, highlights the existence of additional unrecognised species and/or genetically divergent populations in this clade. However, in-depth investigations involving broader sampling are necessary to precisely delineate the range distribution and biogeographic histories of various krait species in the Indian subcontinent.

\subsection{The Clinical Impact of Bungarus Venoms}

Kraits are amongst the deadliest snakes in India and are responsible for nearly $18 \%$ of the annual snakebite cases [2]. In addition to the severe neurotoxic symptoms that are often documented in krait bite victims, atypical symptoms have also been previously reported [4]. The venom of $B$. sindanus was theorised to contain large amounts of myotoxins and/or cardiotoxins as myocardial damages were documented in a young bite victim in Maharashtra, who did not have a previous history of heart disease [4]. While we did not detect any cardiotoxins, the venom of $B$. sindanus was dominated by PLA 2 toxins (Figure 3), some of which have been shown to exhibit highly myotoxic activities [26-28]. Interestingly, trace amounts of cardiotoxins were detected in the venom of B. caeruleus from this region. Moreover, the administration of neostigmine in the aforementioned bite victim of the Sind krait was reported to be ineffective [4]. These findings are consistent with the activities of the $\beta$-bungarotoxin, which constituted a large portion of the venom of $B$. sindanus in these regions. As $\beta$-bungarotoxins destroy the motor nerve terminals, deplete synaptic vesicles, and cause axonal degeneration and flaccid paralysis [29], the administration of neostigmine has been shown to be largely ineffective [30]. In parallel to the prolonged neuromuscular paralysis caused by the action of the presynaptic $\beta$-bungarotoxin, $\alpha$-neurotoxin in krait venoms can target postsynaptic neuronal acetylcholine receptors (nAChR) at the neuromuscular junction [31]. The venom gland transcriptome of B. caeruleus was particularly rich in both Type-I (short) and Type-II (long) $\alpha$-neurotoxin transcripts ( $62 \%$ of all 3 FTxs), and a large proportion of these (66\%) constituted the venom proteome as well. While the venom glands of $B$. sindanus and B. romulusi also transcribed large numbers of $\alpha$-neurotoxins (65\% and $87 \%$ of all 3FTx transcripts), their venoms were surprisingly constituted by a minor fraction of these proteins (14\% and 10\%, respectively). Similarly, structurally complex $\mathrm{k}$-bungarotoxins, which are exclusively found in Bungarus spp., can antagonise neuronal $\mathrm{nAChRs}$, resulting in flaccid paralysis [32]. While a large proportion of $k$-bungarotoxin transcripts were recovered from the venom gland of B. caeruleus $(20 \%)$, only minor amounts were detected in B. romulusi (1.63\%) and were completely absent in the $B$. sindanus transcriptome (Tables S10-S12).

$\mathrm{AChE}$ is yet another important Bungarus venom component that is involved in the rapid hydrolysis of acetylcholine at the neuromuscular junction [33]. Previous studies have reported varied proportions of $\mathrm{AChE}$, ranging from as low as $0.02 \%$ to $12.6 \%$ from closely related Bungarus spp. [34,35]. While Bungarus venom AChEs possess substrate specificity and high catalytic activity [36], they did not exhibit pronounced toxicity or synergy when tested using in vivo models [37]. However, the detection of a significantly higher abundance of $\mathrm{AChE}$ in B. romulusi venoms might insinuate its potential role in snakebite envenoming and warrants further investigation. 


\subsection{The Role of Ecology, Environment and Phylogenetic Histories in Driving Snake Venoms}

Ecology and environment are well-known to influence the composition and potencies of snake venoms [38-42]. Differing biogeographies have been shown to have a significant impact on the venoms of Naja naja and Daboia russelii, two of the medically most important 'big four' snakes [43-49]. However, despite sharing overlapping distribution ranges, at least in some parts of Western India (the precise range overlap is yet to be fully understood), the venom profiles of the investigated cryptic kraits were surprisingly distinct. Even though the differences were mainly in terms of the proportion of 3FTxs and PLA 2 , very distinct toxicity profiles were documented. Consistent with the previous findings [15], B. sindanus venom was extremely toxic to mice, being over 11 times more potent than $B$. caeruleus, which makes it the most toxic snake in the Indian subcontinent and amongst the most toxic snakes in the world. It should be noted that this species has been reported to show a preference for mammalian prey animals over reptiles [4], which could explain the extremely high toxicity of this venom in the mouse model. The venom of B. romulusi was also found to be a lot more potent than that of B. caeruleus. When tested in the murine model, this species was found to be six times more potent than B. caeruleus. Considering the overlapping distribution ranges of these closely related species, the outcomes of toxicity profiling experiments are surprising. While subtle differences in prey-preference, diet breadth and predator pressures cannot be ignored, these results are, perhaps, also suggestive of the roles of phylogenetic histories in driving snake venom compositions and toxicity profiles.

\subsection{Post-Genomic Regulation Shapes Krait Venom Profiles}

Comparative tissue transcriptomics revealed that the venom glands of all three krait species in Southern and Western India were highly similar in their toxin compositions. The venom glands of $B$. sindanus, $B$. caeruleus and $B$. romulusi were highly enriched with PLA $_{2} \mathrm{~S}$ and various functional subtypes of 3FTxs. The only considerable documented difference was with respect to the abundance of $\beta$-bungarotoxin in the venom gland transcriptome of B. sindanus (20\%), whereas those of the other two species had similar amounts of CRISP transcripts (10-13\%). In contrast to their highly similar venom gland transcriptomes, and despite sharing overlapping range distributions (at least in the case of B. caeruleus and $B$. sindanus) and, consequently, very similar environments, the venom proteomes of these kraits were considerably distinct. While the venom of $B$. caeruleus was still enriched with neurotoxic 3 FTxs $(66 \%), B$. sindanus $(52 \%)$ and B. romulusi $(42 \%)$ venoms were largely composed of $\mathrm{PLA}_{2} \mathrm{~s}$. In contrast to this switch from a combination of 3FTx and $\mathrm{PLA}_{2}-$ enriched transcriptome to a largely $\mathrm{PLA}_{2}$-dominated venom proteome in the Sind krait, the abundance of $\beta$-bungarotoxin remained nearly the same $(\sim 12 \%)$. The abundance of this toxin type significantly reduced from nearly $10 \%$ of the venom gland transcriptome to $4 \%$ of the venom proteome in B. romulusi. $\beta$-bungarotoxin has been shown to be responsible for the fatally toxic effects accompanying Bungarus envenomings [50]. However, the precise role of this toxin type in driving the extreme potency of $B$. sindanus remains to be understood. Interestingly, differences between the expressed transcriptomes and venom proteomes have also been reported in other Bungarus spp. in Southeast Asia [20]. However, these changes were attributed to post-translational modifications by the authors, who argued that this might be a result of the differences in the amounts of protein processing enzymes. Since microRNAs (miRNA) have been previously documented to facilitate ontogenetic shifts in snake venom compositions via post-genomic mechanisms [51], future investigations into the miRNA profiles of Indian kraits are warranted to unravel their roles in shaping these contrasting venom profiles.

\subsection{The Need for Regionally Effective Antivenoms}

While the underlying mechanisms driving the evolution of venom remain to be elucidated, the impact of this variation on the preclinical effectiveness of snakebite therapy could not be any clearer. The effectiveness of the PSVPL antivenom in neutralising the fatal effects of B. caeruleus venom $(0.74 \mathrm{mg} / \mathrm{mL})$, which is used in the manufacturing 
process, was well over the marketed neutralising potency $(0.45 \mathrm{mg} / \mathrm{mL})$. Surprisingly, despite exhibiting a venom recognition potential that is very similar to the binding against $B$. caeruleus, the antivenom performed extremely poorly against the venom of the closelyrelated B. romulusi $(0.13 \mathrm{mg} / \mathrm{mL})$. However, consistent with the results for the Rajasthan population $(0.27 \mathrm{mg} / \mathrm{mL})$ [15], the commercial antivenom performed extremely poorly against the venom of $B$. sindanus from Maharashtra $(0.15 \mathrm{mg} / \mathrm{mL})$. In addition to their inability to counter interspecific venom variation, Indian antivenoms have also been shown to be inefficacious in neutralising the intraspecific variation in the venoms of distant B. caeruleus populations $[15,25]$.

These findings very clearly demonstrate the inadequacy of the polyvalent antivenom in conferring cross-neutralisation even against species that are closely related to the 'big four' snakes. Considering the remarkable numbers of medically important snake species in the country, and the diversity of toxin types they secrete, it would be practically difficult to produce a single antivenom product. Moreover, the preclinical outcome of this product is unlikely to improve, as it would be unreasonable to expect the required amounts of neutralising antibodies against the diversity of venoms of the pan-Indian snake species/populations. This is especially true for an antivenom production strategy that has remained virtually unchanged over the past century. While significant efforts are being put into producing recombinant antivenoms with broadly neutralising antibodies that would offer a very effective clinical alternative, they are far from fruition. Therefore, establishing regional venom collection centres in strategically chosen locales across the country, determined by the outcomes of phylogenetic and venomics research, will enable the development of regionally effective antivenoms that are likely to confer protection against the medically important snakes by region. Thus, there is a pressing need to produce regionally effective antivenoms in India to safeguard the lives of hundreds of thousands of snakebite victims.

\section{Conclusions}

In conclusion, phylogenetic reconstructions of evolutionary histories of phenotypically similar cryptic kraits in Southern and Western India provided fascinating insights. Bayesian and maximum-likelihood analyses using mitochondrial markers revealed a new species of krait in Southern India, which we named Romulus' krait (B. romulusi). These analyses also revealed that the krait with 17 mid-body dorsal scale rows in Western India is not a subspecies of the Sind Krait (B. sindanus walli) or a distinct species (B. walli) as previously believed but was rather genetically very similar to $B$. sindanus in Pakistan. Moreover, venom proteomics and comparative tissue transcriptomics experiments unravelled completely contrasting venom profiles in each krait species. While the venom proteomic composition differed significantly between the three species, their transcriptomes were largely similar, highlighting the possible role of post-genomic regulatory mechanisms in shaping their venoms. In vitro and in vivo experiments, assessing the effectiveness of commercial Indian antivenoms in countering these distinct krait venoms, revealed a severe shortcoming. While the antivenom preclinically neutralised $B$. caeruleus venom effectively, its efficiency against the venoms of $B$. sindanus and B. romulus $i$ was severely limited. Taken together, our findings highlight the importance of phylogenetic studies in identifying medically important species/populations and the urgent need for regionally-effective antivenoms in India.

\section{Material and Methods}

\subsection{Sampling Permits, Snake Venoms and Antivenoms}

One adult female snake of each species was wild-caught from the Pune district in Maharashtra with due approval from the Maharashtra State Forest Department (Desk22 (8)/WL/Research/CR-60 (17-18)/2708/2018-2019) (Figure 1A). In addition, a female krait was also caught from Southern Karnataka with appropriate permission from the Karnataka State Forest Department (PCCF(WL)/E2/CR06/2018-19). Individually collected 
venoms were flash-frozen immediately, lyophilised and stored at $-80{ }^{\circ} \mathrm{C}$ until further use. Post venom extraction, snakes were housed for three days in captivity and venom glands were collected on the fourth day. Snakes were humanely euthanised with a single intracardiac dose of sodium pentobarbital $(100 \mathrm{mg} / \mathrm{kg})$, followed by the surgical extraction of venom glands and other physiological tissues. Tissue samples were immediately flashfrozen and stored at $-80{ }^{\circ} \mathrm{C}$ until use. The Bradford assay [52] was used to determine the protein concentrations of venom and commercial antivenoms with Bovine Serum Albumin (BSA) and Bovine Gamma Globulin (BGG) as standards, respectively (Tables S1 and S13). Additional details of venom and antivenom samples investigated in this study are provided in Tables S1 and S13, respectively. Given that the Bungarus spp. are protected in India under the Schedule IV of the Wildlife (Protection) Act (1972), we were only granted permission by the Karnataka Forest Department to euthanise a single individual for venom gland transcriptomics (under the purview of licensed 'hunting and killing'). Tissue samples, including the heart tissue that was used for DNA isolation, have been deposited with the Bombay Natural History Society (BNHS) as paratypes: heart (BNHS 3611) and intestine (BNHS 3612). However, in case any of the live specimens under captivity suffer death by natural causes, an intact specimen will be housed as a topotype in the museum at the Centre for Ecological Sciences, IISc, Bangalore (CES-BNHS 3611-02), and additional specimens (if and when available) will be deposited to BNHS with due permissions from the Forest Department. Full-body images of B. romulusi have been submitted to MorphoBank (\#3897).

\subsection{Ethical Clearances}

The toxicity profiles of the venom samples and the neutralisation potencies of commercial Indian antivenoms were estimated in the murine model, as per the World Health Organisation (WHO)-recommended protocols. Experiments were conducted on male CD-1 mice (18-22 g) after acquiring due approval from CPCSEA and IAEC: CAF/Ethics/770/2020 (approval date: 16 October 2020). Throughout the course of the experiment, animals were housed in the Central Animal Facility at IISc (48/GO/ReBi/SL/1999/CPCSEA; 11-03-1999). The ability of Bungarus venoms in inducing coagulopathies in human blood was evaluated after obtaining necessary approvals from the Institutional Human Ethics Committee (IHEC No: 5-24072019; approval date: 24 July 2019), IISc.

\subsection{DNA Isolation and Sequencing}

Genomic DNA was isolated from the heart muscle tissue using the Xpress DNA Tissue kit following the manufacturer's recommendations (MagGenome, Leeds, UK). The quality of the isolated DNA was evaluated by estimating the absorbance ratio at $260 \mathrm{~nm}$ and $280 \mathrm{~nm}$ wavelengths in an Epoch 2 microplate spectrophotometer (BioTek Instruments, Inc., Winooski, VT, USA) and visualisation on $1 \%$ agarose gel electrophoresis. Polymerase Chain Reaction (PCR) was performed on a ProFlex PCR System (Thermo Fisher Scientific, Waltham, MA, USA) to amplify specific regions of two mitochondrial markers (ND4 and cyt $b$ ) using universal primers [53,54] (Table S16). PCR reaction mixtures $(50 \mu \mathrm{L})$ contained $1 \mu \mathrm{L}$ of template DNA ( $50 \mathrm{ng}$ ), $25 \mu \mathrm{L}$ of Taq DNA Polymerase Mastermix (Tris- $\mathrm{HCl} \mathrm{pH}$ 8.5, $\left(\mathrm{NH}_{4}\right)_{2} \mathrm{SO}_{4}, 3 \mathrm{mM} \mathrm{MgCl}, 0.2 \%$ Tween $20,3 \mu \mathrm{L}$ of $25 \mathrm{mM} \mathrm{MgCl}_{2}, 0.4 \mathrm{mM}$ dNTPs, Amplicon Taq polymerase), $2.5 \mu \mathrm{L}$ each of forward and reverse primers and $19 \mu \mathrm{L}$ of nuclease-free water. For PCR amplification, the following thermal profiles were used: initial denaturation at $94{ }^{\circ} \mathrm{C}$ for $5 \mathrm{~min}$, then 35 cycles of denaturation $\left(94{ }^{\circ} \mathrm{C}\right.$ for $\left.30 \mathrm{~s}\right)$, annealing $\left(\mathrm{T}_{\mathrm{A}}\right.$ for $\left.35 \mathrm{~s}\right)$ and extension $\left(72{ }^{\circ} \mathrm{C}\right.$ for $2 \mathrm{~min}$ ), followed by a final step of extension for $10 \mathrm{~min}$ at $72{ }^{\circ} \mathrm{C}$. Following gel purification using the QIAquick PCR and Gel Cleanup Kit (Qiagen, Hilden, Germany), amplicons were sequenced on the Applied Biosystems 3730xl platform (Thermo Fisher Scientific, Waltham, MA, USA) and the sequence data were acquired with Sequence Scanner Software v2.0. Sequences generated in this study have been deposited to the GenBank database, and the data along with accession numbers have been provided in Supplemental Files S1 and S2. 


\subsection{Phylogenetic Reconstructions}

Nucleotide datasets were assembled for both genes by retrieving additional sequences from NCBI's GenBank repository. Sequences were aligned using Clustal-Omega [55]. For reconstructing the phylogenetic histories of Bungarus spp., we first used the ML-based approach implemented in the PhyML package [56]. The best nucleotide substitution model for reconstruction was identified using the Smart Model Selection (SMS) tool on the ATGC server [57] with the Subtree-Pruning-Regrafting (SPR) method for searching tree topologies and 100 bootstrapping replicates for the evaluation of node support. The Bayesian inference-based phylogeny was also estimated using MrBayes 3.2.7 [58,59]. The analysis was executed on four independent runs, each with nine parallel Markov chain simulations, running for 10 million generations or until the convergence of chains (i.e., 0.01 standard deviation of split frequencies). The trees and the corresponding parameter estimates were sampled every 100 th generation, of which, $25 \%$ were discarded as burn-in. A majority-rule consensus tree and the posterior probability of each node were estimated using trees selected post-burn-in. We further estimated the evolutionary divergence between ND4 and cyt $b$ sequences using the Maximum Composite Likelihood model [60] in MEGA X [61] with 500 bootstrap replicates. Additionally, $p$-distances were also calculated in MEGA X [61].

\subsection{Gel Electrophoresis}

Electrophoretic separation of venom samples was accomplished on SDS-PAGE. Briefly, venoms normalised for protein content $(12 \mu \mathrm{g})$ were resolved in a $12.5 \%$ gel under reducing conditions, followed by staining with Coomassie Brilliant Blue R-250 (Sisco Research Laboratories Pvt. Ltd., Mumbai, MH, India) and imaging under an iBright CL1000 (Thermo Fisher Scientific, Waltham, MA, USA) gel documentation system. The densitometric analyses of the gel bands were performed using the ImageJ software [62].

\subsection{Liquid Chromatography-Tandem Mass Spectrometry (LC-MS/MS)}

Crude snake venom samples (50 $\mu \mathrm{g}$ ) in $25 \mathrm{mM}$ ammonium bicarbonate were reduced with $10 \mathrm{mM}$ dithiothreitol for $30 \mathrm{~min}$ at $37^{\circ} \mathrm{C}$, alkylated with $100 \mathrm{mM}$ iodoacetamide for $30 \mathrm{~min}$ in the dark and digested with trypsin $(0.2 \mu \mathrm{g} / \mu \mathrm{L})$ at $37^{\circ} \mathrm{C}$ overnight, in a total volume of $50 \mu \mathrm{L}$. The reaction was stopped using $0.1 \%$ formic acid, and desalting was carried out to remove the buffer salt and detergent using ZipTip with acetonitrile. The resulting tryptic peptide mixtures were separated using the Thermo EASY nLC 1200 series system (Thermo Fisher Scientific, Waltham, MA, USA) coupled online with a Thermo Orbitrap Fusion ${ }^{\mathrm{TM}}$ Mass Spectrometer (Thermo Fisher Scientific, Waltham, MA, USA). We loaded $0.5 \mu \mathrm{g}$ of peptide mixture on a $50 \mathrm{~cm} \times 75 \mu \mathrm{m} \mathrm{C18}(3 \mu \mathrm{m}, 100 \AA)$ nano-LC column. The mobile phase solution consisted of $0.1 \%$ formic acid in HPLC grade water (solution A) and an elution buffer of $0.1 \%$ formic acid in $80 \%$ acetonitrile (solution B). The flow rate of solution B was set to $300 \mathrm{~nL} / \mathrm{min}$ and was used in the following concentrations: $10-45 \%$ over $98 \mathrm{~min}, 45-95 \%$ over $4 \mathrm{~min}$ and $95 \%$ over $18 \mathrm{~min}$. MS spectra were acquired in positive mode at $2.0 \mathrm{kV}$, with a capillary temperature of $200{ }^{\circ} \mathrm{C}$, using $1 \mu$ scan in the range $375-1700$ $\mathrm{m} / \mathrm{z}$, maximum injection time of $50 \mathrm{~ms}$ and resolution of 120,000. Fragment scans (MS/MS) were performed using an ion trap detector with high collision energy fragmentation $(30 \%)$, scan range between $100-2000 \mathrm{~m} / \mathrm{z}$ and maximum injection time of $35 \mathrm{~ms}$. For the identification of various toxin families in the proteomic profiles of venoms, raw MS/MS spectra were searched against the National Center for Biotechnology Information's (NCBI) non-redundant (nr) database (Serpentes: 8570; November 2020), as well as the venom gland transcriptomes generated in this study, using PEAKS Studio X Plus (Bioinformatics Solutions Inc., Waterloo, ON, Canada). Parent and fragment mass error tolerances were set at 10 parts per million (ppm) and $0.6 \mathrm{Da}$, respectively. Cysteine carbamidomethylation was set as fixed modification while methionine oxidation and deamidation of asparagine or glutamine were set as variable modifications. A maximum of 2 missed cleavages by trypsin in the semispecific mode were allowed. Filtration parameters for match acceptance were set to FDR $0.1 \%$, detection of $\geq 1$ unique peptide and $-10 \lg P$ protein score $\geq 40$. Hits 
with at least one unique matching peptide were considered for downstream analyses. Mass spectrometry data have been deposited to the ProteomeXchange Consortium via the PRIDE [63] partner repository, with data identifier: PXD023127. The relative abundance of each toxin hit in a sample was determined by its area under the spectral intensity curve (AUC) obtained from PEAKS Studio analyses, relative to the total AUC for all toxin hits. The relative abundance of a toxin hit $(\mathrm{X})$ was calculated as follows:

$$
\text { Relative abundance of toxin hit } X(\%)=\frac{A U C \text { of toxin hit } X}{\text { Total AUC of all toxin hits }} \times 100
$$

The results of mass spectrometry analyses are provided in Supplemental File S3.

\subsection{RNA Isolation, Library Construction and RNA Sequencing}

Total RNA was isolated from venom glands and physiological tissues of freshly euthanised snakes using the TRIzol ${ }^{\mathrm{TM}}$ Reagent (Invitrogen, Thermo Fisher Scientific, Waltham, MA, USA) according to the manufacturer's protocol (Table S17). Contaminant DNA was removed from the isolated RNA samples by treatment with Turbo DNase (Thermo Fisher Scientific, Waltham, MA, USA), followed by another round of extraction with the TRIzol ${ }^{\mathrm{TM}}$ Reagent to remove the DNase enzyme. Quantification of RNA was performed using an Epoch 2 microplate spectrophotometer (BioTek Instruments, Inc., Winooski, VT, USA) and Qubit Fluorometer (RNA High Sensitivity kit: Cat\# Q32852; Agilent Technologies, Santa Clara, CA, USA), while the integrity was assessed on the Agilent 4200 TapeStation system using RNA HS ScreenTape (Cat\# 5067-5579; Agilent Technologies, Santa Clara, CA, USA). With the exception of a physiological tissue RNA (RIN: 7), samples with an RNA Integrity Number (RIN) of $\geq 8$ were down-selected for RNA sequencing (Table S17).

Prior to the library preparation, the ribosomal RNA (rRNA) was removed with the help of NEBNext Poly(A) mRNA Magnetic Isolation Module, followed by fragmentation of the selected mRNA in the presence of divalent cations at elevated temperatures. Library preparation was then performed using the NEBNext ${ }^{\circledR}$ Ultra $^{\text {TM }}$ RNA Library Prep Kit for Illumina ${ }^{\circledR}$, following the manufacturer's protocol. The resultant cDNA libraries were amplified by subjecting them to 13 cycles of PCR. Following the purification of PCR products, qualitative and quantitative assessments were performed using Qubit High Sensitivity Assay (Cat\# Q32852; Agilent Technologies) and D1000 DNA ScreenTapes (Cat\# 5067-5582; Agilent Technologies) on a TapeStation, respectively. The resultant libraries were sequenced on the HiSeq X System (Illumina, San Diego, CA, USA) to generate at least 50 million paired-end $(2 \times 150 \mathrm{bp})$ reads per sample. The raw sequencing data generated in this project has been deposited to the Sequence Read Archive (SRA) at NCBI (Bioproject: PRJNA681550; SRA: SUB8677374, SUB8648213 and SUB8655883).

\subsection{Quality Filtering, Transcriptome Assembly and Transcript Annotation}

Prior to the transcriptome assembly, Illumina's basespace pipeline was used for demultiplexing and filtering high-quality sequencing reads. This was followed by quality filtering steps in Trimmomatic v0.39 [64], where the adapter sequences, leading and trailing low-quality bases $(<3)$, short reads $(<20$ bases) and low-quality reads $(<25$; sliding window 4) were removed. The quality of FASTQ sample files before and after trimming was validated using FASTQC v0.11.9 [65]. Quality-filtered reads were then de novo assembled into contigs using Trinity v2.11.0 [66] with the following parameters: $\mathrm{k}$-mer $=25$, minimum $\mathrm{k}$-mer coverage $=1$, minimum contig length $=200$, pair distance $=500$ and the maximum number of reads per graph $=200,000$. The quality of the assembled transcriptome was evaluated by aligning reads back onto the transcriptome using BowTie v2.4.2 [67]. This was followed by the prediction of coding regions in transcripts that encode a minimum of 30 amino acids using TransDecoder v5.5.0 [68]. These coding regions were then annotated by performing BLAST searches [69] against the NCBI-nr database (November 2020; Serpentes (taxid: 8570)). 


\subsection{Transcript Quantification and Differential Expression Analyses}

Following the alignment of reads back onto the transcriptome with BowTie v2.4.2 [67], alignment-based transcript abundance quantification, expressed in fragments per kilobase of exon per million fragments mapped (FPKM), was performed using RNA-Seq by the Expectation-Maximization (RSEM v1.3.3) tool [70]. Pairwise differential expression analysis was performed on the RSEM normalised count data using a novel nonparametric approach implemented in the NOISeq $R$ package [71,72]. Genes were identified as differentially expressed when they met a predefined fold-change $(\geq 2)$ and statistical probability $(p \geq 0.9)$ cutoffs.

\subsection{Venom Induced Coagulopathy}

The abilities of Bungarus venoms in altering blood coagulation cascades by affecting the two major coagulation pathways (i.e., intrinsic and extrinsic pathways) were evaluated by performing activated partial thromboplastin time (aPTT) and prothrombin time (PT) tests, respectively. Briefly, whole blood collected from healthy male volunteers was centrifuged at $3000 \times \mathrm{g}$ for $10 \mathrm{~min}$ at $4{ }^{\circ} \mathrm{C}$ to separate red blood cells (RBC) and collect the platelet-poor plasma (PPP). Four concentrations of Bungarus venoms $(5 \mu \mathrm{g}, 10 \mu \mathrm{g}$, $20 \mu \mathrm{g}$ and $40 \mu \mathrm{g}$ ) were mixed with calcium thromboplastin and activated cephaloplastin reagent with calcium dichloride $\left(\mathrm{CaCl}_{2}\right)$ (Liquicelin-E; Tulip diagnostics, Mumbai, $\mathrm{MH}$, India) to measure PT and aPTT values, respectively. Hemostar XF 2.0 coagulometer (Tulip Diagnostics, Mumbai, MH, India) was used to measure the time taken for the formation of the first fibrin clot.

\subsection{Haemolytic Assay}

The ability of Bungarus venoms in destroying RBCs was assessed following a previously described protocol $[15,73]$. Briefly, RBCs from freshly collected human blood were separated and washed five times using 1 X PBS buffer (pH 7.4). The RBC pellet obtained was resuspended gently in PBS at a ratio of 1:10 and incubated with various concentrations of venoms at $37^{\circ} \mathrm{C}$. Following a $24 \mathrm{~h}$ incubation, the supernatant was collected after centrifugation at $3000 \times g$ for $10 \mathrm{~min}$ at $4{ }^{\circ} \mathrm{C}$. The absorbance of the supernatant measured at $540 \mathrm{~nm}$ was used to calculate the haemolytic activity of the venoms relative to $0.5 \%$ Triton $\mathrm{X}$ (positive control). The activities of all the samples were assessed in triplicates.

\subsection{Enzyme-Linked Immunosorbent Assay (ELISA)}

The in vitro binding abilities of commercial Indian antivenoms against the Bungarus venoms were determined using indirect ELISA as described before [15,74]. We coated 96-well immunoplates with crude venoms (100 ng) diluted in the carbonate buffer ( $\mathrm{pH}$ 9.6), followed by overnight incubation at $4{ }^{\circ} \mathrm{C}$. The plates were washed six times with Trisbuffered saline ( $0.01 \mathrm{M}$ Tris $\mathrm{pH} 8.5,0.15 \mathrm{M} \mathrm{NaCl})$ and $1 \%$ Tween 20 (TBST), followed by the addition of blocking buffer (5\% skimmed milk in TBST). After the completion of three hours of incubation at room temperature, the plates were again washed with TBST $(n=6)$, followed by the addition of various dilutions of commercial Indian antivenoms (1:4 to 1:312500). The plates were then incubated overnight at $4{ }^{\circ} \mathrm{C}$. Unbound primary antibodies were washed off with a series of TBST washes $(n=6)$ the next day, followed by the addition of $100 \mu \mathrm{L}$ horseradish peroxidase (HRP)-conjugated, rabbit anti-horse secondary antibody (Sigma-Aldrich, St. Louis, MO, USA; 1:1000 dilution in PBS buffer). The plates were incubated for two hours at RT and 2,2'-Azino-bis(3-ethylbenzothiazoline-6-sulfonic acid) substrate solution (Sigma-Aldrich, St. Louis, MO, USA) was added for colour development. The absorbance, which is directly proportional to the venom recognition capability of the antivenom, was measured at $405 \mathrm{~nm}$ in an Epoch 2 microplate spectrophotometer (BioTek Instruments, Inc., Winooski, VT, USA). The statistical significance of the result was evaluated by two-way ANOVA with Tukey's and Dunnett's multiple comparisons in GraphPad Prism (GraphPad Software 8.0, San Diego, CA, USA, www.graphpad.com). 
IgG from an unimmunised horse was used to calculate the non-specific binding cut off as described previously $[15,74]$.

\subsection{Immunoblotting}

To measure the Bungarus venom recognition potential of commercial Indian antivenoms, we performed immunoblotting experiments [15,74]. Following the separation of venom proteins on a $12.5 \%$ SDS-PAGE gels, proteins were transferred onto a nitrocellulose membrane using the Trans-Blot Turbo Transfer System (BioRad, Hercules, CA, USA) as per the instructions provided by the manufacturer. The reversible Ponceau $S$ stain was used to confirm transfer efficacy, and then the membrane was blocked with a blocking solution ( $5 \%$ skimmed milk in TBST) at $4{ }^{\circ} \mathrm{C}$ overnight. On the next day, the membrane was washed with TBST six times and incubated overnight with a fixed concentration of commercial antivenom $(1: 200)$ at $4{ }^{\circ} \mathrm{C}$. On the third day, after a series of TBST washes $(n=6)$, the membrane was incubated with HRP-conjugated rabbit anti-horse secondary antibody at 1:2000 dilution for two hours. Finally, an enhanced chemiluminescent substrate was used to visualise the blotting results in an iBright CL1000 gel imaging system (Thermo Fisher Scientific, Waltham, MA, USA). The densitometry analyses of the bands were performed using ImageJ [62].

\subsection{The Intravenous Median Lethal Dose $\left(L D_{50}\right)$}

To evaluate the venom potencies of Bungarus species, WHO-recommended murine assays [75] were conducted and $\mathrm{LD}_{50}$ value (or the amount of venom required to kill $50 \%$ of the test population) was determined. Briefly, various concentrations $(n=5)$ of crude venom samples in physiological saline $(0.9 \% \mathrm{NaCl})$ were injected intravenously into the caudal vein of male CD-1 mice ( $200 \mu \mathrm{L} /$ mouse). The number of dead and surviving mice were recorded $24 \mathrm{~h}$ post venom administration and the $\mathrm{LD}_{50}$, and $95 \%$ confidence intervals were calculated using Probit statistics [76].

\subsection{The Median Effective Dose ( $\left.E D_{50}\right)$ of Antivenom}

The preclinical efficacies of commercial Indian antivenoms in neutralising the fatal effects of Bungarus venoms were determined by estimating the $\mathrm{ED}_{50}$ value, which represents the minimum amount of antivenom required to protect $50 \%$ of the test population injected with the lethal dose of venom [75]. To greatly reduce the number of animals sacrificed in these experiments, only the antivenom manufactured by Premium Serums, which exhibited better venom recognition potential in comparison to the Haffkine antivenom, was tested in these experiments. Various volumes of the antivenom, incubated for $30 \mathrm{~min}$ at $37^{\circ} \mathrm{C}$ with a predefined challenge dose of venom $\left(5 X \mathrm{LD}_{50}\right)$, were intravenously administered into male CD-1 mice (18-22 g; 5 mice per group). $\mathrm{ED}_{50}$ values and $95 \%$ confidence intervals were calculated using Probit statistics based on the number of surviving and dead mice $24 \mathrm{~h}$ post-venom-antivenom administration [76]. The neutralisation antivenom potencies were calculated as defined previously $[15,77,78]$.

Supplementary Materials: The following are available online at https:/ / www.mdpi.com/2072-6 651/13/1/69/s1, Figure S1. The Bayesian cytochrome b phylogeny of Bungarus species; Figure S2. Maximum likelihood phylogeny (ND4 marker) for Bungarus species; Figure S3. Maximum likelihood phylogeny (cyt $b$ marker) for Bungarus species; Figure S4. Electrophoretic separation of Bungarus venoms under non-reducing and reducing conditions; Figure S5. Pharmacological activities of Bungarus venoms from Western India; Figure S6. Western blotting of Indian polyvalent antivenoms against the cryptic Bungarus venoms; Table S1. Details of Bungarus venom samples investigated in this study; Table S2. A: Evolutionary sequence divergence estimated using the maximum composite likelihood (MCL) model for ND4 marker; Table S3. Evolutionary sequence divergence estimated using the MCL model for cytochrome $b$ marker; Table S4. Evolutionary divergence estimated as pdistance for ND4 marker; Table S5. Evolutionary divergence estimated as p-distance for cytochrome $b$ marker; Table S6. The proteomic composition of B. sindanus venom; Table S7. The proteomic composition of B. caeruleus venom; Table S8. The proteomic composition of B. romulusi venom; 
Table S9. Tissue transcriptome sequencing and assembly; Table S10. Venom gland toxin transcripts from Bungarus sindanus; Table S11. Venom gland toxin transcripts from Bungarus caeruleus; Table S12. Venom gland toxin transcripts from Bungarus romulusi; Table S13. Details of antivenom samples investigated in this study; Table S14. Toxicity profiles of Bungarus species from Western India; Table S15. Neutralisation potencies of commercial Indian polyvalent antivenoms against Bungarus venoms; File S1. Multiple sequence alignment for Bungarus ND4 gene; File S2. Multiple sequence alignment for Bungarus cyt $b$ gene; File S3. Results of proteomic analyses of Bungarus venoms.

Author Contributions: Conceptualisation: K.S.; Resources: K.S., A.C., G.M., A.K.; Investigation: K.S., S.K., R.R.S.L., S.A., P.D., V.S., A.C.; Data Analysis: K.S., S.K., R.R.S.L., S.A., P.D., V.S., G.M., A.C.; Writing: K.S.; Funding Acquisition: K.S. All authors have read and agreed to the published version of the manuscript.

Funding: This work was supported by the DBT/Wellcome Trust India Alliance Fellowship [grant number IA/I/19/2/504647] awarded to K.S. This work was also supported by the following grants: Department for International Development (DFID: grant IAVI/BES/KASU/0002) and DST-FIST (SR/FST/LS-II/2018/233). S.L. and V.S. acknowledge the funding support from MHRD. S.A. was supported by the DBT-RA fellowship.

Institutional Review Board Statement: Protocols for animal experimentation complied with the guidelines issued by World Health Organisation (WHO) and Committee for the Purpose of Control and Supervision of Experiments on Animals (CPCSEA) and were approved by the Institutional Animal Ethics Committee (IAEC) of Indian Institute of Science [IISc; (48/GO/ReBi/SL/1999/CPCSEA; 11-03-1999)], Bangalore [CAF/Ethics/770/2020; 16/10/2020]. Blood was drawn from human volunteers for testing the coagulopathic effects of Bungarus venoms following protocols that complied with the guidelines of the Institutional Human Ethics Committee (IHEC), IISc and were approved by IHEC (IHEC No:5-24072019; 24/07/2019).

Informed Consent Statement: Informed consent was obtained from all subjects involved in the study.

Data Availability Statement: The B. romulusi image data presented in this study is openly available in Morphbank (\#3897). The DNA sequence data generated is accessible through NCBI Genbank database. The raw proteomics data can be found at PRIDE Database (Accession No: PXD023127). The transcriptomics data presented in this study can be openly accessed via Sequence Read Archive (SRA) at NCBI (Bioproject: PRJNA681550; SRA: SUB8677374, SUB8648213 and SUB8655883).

Acknowledgments: The authors are thankful to Arun Khochare, Suchitra Suryanvanshi Patil and Karthik for invaluable veterinary assistance. For providing assistance with sample collection, the authors are thankful to Tejas Khaire, Mahesh Deshpande, Rajendra Pardeshi, Sumanth Madhav, Gowri Shanker, Sanjeev Pednekar and Aditya Malladi. The authors are thankful to Ashwin Iyer and Naeem Shaikh for their help with certain experiments, as well as to Eric Smith (University of Texas Arlington) and Muhammad Rizwan Ashraf (the University of Veterinary and Animal Sciences, Pakistan) for sharing sequences. We are thankful to Praveen Karanth (IISc), David Gower (NHM, London) and Rahul Khot (BNHS) for their valuable inputs. We are thankful to the State forest departments of Maharashtra and Karnataka for granting permissions, providing space for the work and for their invaluable assistance during sample collection. For contributing various photographs to this manuscript, we are thankful to Ajay Kartik (Figure 1: B. caeruleus), Shubham Adhikari (Figure 1: B. sindanus), Gerard Martin (Figures 1, 2 and 6: B. romulusi) and Ashok Captain (Figures 2 and 6: B. caeruleus, B. sindanus, and B. fasciatus).

Conflicts of Interest: The authors declare no conflict of interest.

\section{References}

1. Warrell, D.A.; Gutierrez, J.M.; Calvete, J.J.; Williams, D. New approaches \& technologies of venomics to meet the challenge of human envenoming by snakebites in India. Indian J. Med. Res. 2013, 138, 38-59. [PubMed]

2. Suraweera, W.; Warrell, D.; Whitaker, R.; Menon, G.; Rodrigues, R.; Fu, S.H.; Begum, R.; Sati, P.; Piyasena, K.; Bhatia, M.; et al. Trends in snakebite deaths in India from 2000 to 2019 in a nationally representative mortality study. eLife 2020, 9, e54076. [CrossRef] [PubMed]

3. Dixon, R.W.; Harris, J.B. Nerve terminal damage by beta-bungarotoxin: Its clinical significance. Am. J. Pathol. 1999, 154, 447-455. [CrossRef]

4. Pillai, L.V.; Ambike, D.; Husainy, S.; Khaire, A.; Captain, A.; Kuch, U. Severe Neurotoxic Envenoming and Cardiac Complications after the Bite of a 'Sind Krait' (Bungarus cf. sindanus) in Maharashtra, India. Trop. Med. Health 2012, 40, 103-108. [PubMed] 
5. Pandey, D.P.; Sharma, S.K.; Alirol, E.; Chappuis, F.; Kuch, U. Fatal neurotoxic envenomation following the bite of a greater black krait (Bungarus niger) in Nepal: A case report. J. Venom. Anim. Toxins Incl. Trop. Dis. 2016, 22, 19. [CrossRef]

6. Khan, S. Taxonomic notes on Bungarus caeruleus (Schneider) and Bungarus sindanus Boulenger. Snake 1985, 17, 71-78.

7. Whitaker, R.; Captain, A. Snakes of India: The Field Guide; Draco Books: Totnes, UK, 2004.

8. Vyas, R. Unusual marking pattern in krait Bungarus sindanus. Cobra 1998, 32, 34-35.

9. Boulenger, G.A. A new krait from Sind (Bungarus sindanus). J. Bombay Nat. Hist. Soc. 1897, 11, 73-74.

10. Wall, F. A new krait from Oudh (Bungarus walli). J. Bombay Nat. Hist. Soc. 1907, 17, 608-611.

11. Wallach, V.; Williams, K.L.; Boundy, J. Snakes of the World: A Catalogue of Living and Extinct Species; Taylor and Francis, CRC Press: Milton, UK, 2014.

12. Ashraf, M.R.; Nadeem, A.; Smith, E.N.; Javed, M.; Smart, U.; Yaqub, T.; Hashmi, A.S.; Thammachoti, P. Phylogenetic analysis of the Common Krait (Bungarus caeruleus) in Pakistan based on mitochondrial and nuclear protein coding genes. Amphib. Reptile Conserv. 2019, 13, 203-211.

13. Patra, A.; Chanda, A.; Mukherjee, A.K. Quantitative proteomic analysis of venom from Southern India common krait (Bungarus caeruleus) and identification of poorly immunogenic toxins by immune-profiling against commercial antivenom. Expert Rev. Proteom. 2019, 16, 457-469. [CrossRef] [PubMed]

14. Oh, A.M.F.; Tan, C.H.; Tan, K.Y.; Quraishi, N.H.; Tan, N.H. Venom proteome of Bungarus sindanus (Sind krait) from Pakistan and in vivo cross-neutralization of toxicity using an Indian polyvalent antivenom. J Proteom. 2019, 193, 243-254. [CrossRef] [PubMed]

15. Laxme, R.S.; Khochare, S.; de Souza, H.F.; Ahuja, B.; Suranse, V.; Martin, G.; Whitaker, R.; Sunagar, K. Beyond the 'big four': Venom profiling of the medically important yet neglected Indian snakes reveals disturbing antivenom deficiencies. PLoS Negl. Trop. Dis. 2019, 13, e0007899.

16. Chu, C.C.C.S.; Liau, M.Y.; Chen, Y.H. Diversity of the ß-Bungarotoxin Family. J. Toxicol. Toxin Rev. 1996, 15, 353-368. [CrossRef]

17. Aird, S.D. Snake venom dipeptidyl peptidase IV: Taxonomic distribution and quantitative variation. Comp. Biochem. Physiol. B Biochem. Mol. Biol. 2008, 150, 222-228. [CrossRef]

18. Siang, A.S.; Doley, R.; Vonk, F.J.; Kini, R.M. Transcriptomic analysis of the venom gland of the red-headed krait (Bungarus flaviceps) using expressed sequence tags. BMC Mol. Biol. 2010, 11, 24. [CrossRef]

19. Jiang, Y.; Li, Y.; Lee, W.; Xu, X.; Zhang, Y.; Zhao, R.; Zhang, Y.; Wang, W. Venom gland transcriptomes of two elapid snakes (Bungarus multicinctus and Naja atra) and evolution of toxin genes. BMC Genom. 2011, 12, 1. [CrossRef]

20. Yin, X.; Guo, S.; Gao, J.; Luo, L.; Liao, X.; Li, M.; Su, H.; Huang, Z.; Xu, J.; Pei, J.; et al. Kinetic analysis of effects of temperature and time on the regulation of venom expression in Bungarus multicinctus. Sci. Rep. 2020, 10, 14142. [CrossRef]

21. Sunagar, K.; Columbus-Shenkar, Y.Y.; Fridrich, A.; Gutkovich, N.; Aharoni, R.; Moran, Y. Cell type-specific expression profiling unravels the development and evolution of stinging cells in sea anemone. BMC Biol. 2018, 16, 108. [CrossRef]

22. Gowtham, Y.J.; Kumar, M.S.; Girish, K.S.; Kemparaju, K. Hemostatic interference of Indian king cobra (Ophiophagus hannah) Venom. Comparison with three other snake venoms of the subcontinent. Biochemistry 2012, 77, 639-647. [CrossRef]

23. Das, D.; Urs, N.; Hiremath, V.; Vishwanath, B.S.; Doley, R. Biochemical and biological characterization of Naja kaouthia venom from North-East India and its neutralization by polyvalent antivenom. J. Venom. Res. 2013, 4, 31-38. [PubMed]

24. Kumar, M.S.; Devaraj, V.R.; Vishwanath, B.S.; Kemparaju, K. Anti-coagulant activity of a metalloprotease: Further characterization from the Indian cobra (Naja naja) venom. J. Thromb. Thrombolysis 2010, 29, 340-348. [CrossRef] [PubMed]

25. Oh, A.M.F.; Tan, C.H.; Ariaranee, G.C.; Quraishi, N.; Tan, N.H. Venomics of Bungarus caeruleus (Indian krait): Comparable venom profiles, variable immunoreactivities among specimens from Sri Lanka, India and Pakistan. J. Proteom. 2017, 164, 1-18. [CrossRef] [PubMed]

26. Summers, B.A. Myotoxic effects of krait venoms. In Proceedings of the Association of British Neurologists Meeting, Newcastle upon Tyne, UK, 22-24 September 1987.

27. Faiz, A.; Ghose, A.; Ahsan, F.; Rahman, R.; Amin, R.; Hassan, M.U.; Chowdhury, M.A.W.; Kuch, U.; Rocha, T.; Harris, J.B.; et al. The greater black krait (Bungarus niger), a newly recognized cause of neuro-myotoxic snake bite envenoming in Bangladesh. Brain 2010, 133, 3181-3193. [CrossRef] [PubMed]

28. Gutierrez, J.M.; Lomonte, B. Phospholipase A2 myotoxins from Bothrops snake venoms. Toxicon 1995, 33, 1405-1424. [CrossRef]

29. Ranawaka, U.K.; Lalloo, D.G.; de Silva, H.J. Neurotoxicity in snakebite-the limits of our knowledge. PLoS Negl. Trop. Dis. 2013, 7, e2302. [CrossRef]

30. Anil, A.; Singh, S.; Bhalla, A.; Sharma, N.; Agarwal, R.; Simpson, I.D. Role of neostigmine and polyvalent antivenom in Indian common krait (Bungarus caeruleus) bite. J. Infect. Public Health 2010, 3, 83-87. [CrossRef]

31. Mebs, D.; Claus, I. Amino acid sequences and toxicities of snake venom components. In Snake Toxins; Harvey, A.L., Ed.; Pegamon Press: New York, NY, USA, 1991; pp. 425-447.

32. Sunagar, K.; Jackson, T.N.; Undheim, E.A.; Ali, S.A.; Antunes, A.; Fry, B.G. Three-fingered RAVERs: Rapid Accumulation of Variations in Exposed Residues of snake venom toxins. Toxins 2013, 5, 2172-2208. [CrossRef]

33. Cousin, X.; Bon, C. Acetylcholinesterase from snake venom as a model for its nerve and muscle counterpart. J. Nat. Toxins 1999, 8, 285-294.

34. Ziganshin, R.H.; Kovalchuk, S.I.; Arapidi, G.P.; Starkov, V.G.; Hoang, A.N.; Thi Nguyen, T.T.; Nguyen, K.C.; Shoibonov, B.B.; Tsetlin, V.I.; Utkin, Y.N. Quantitative proteomic analysis of Vietnamese krait venoms: Neurotoxins are the major components in Bungarus multicinctus and phospholipases A2 in Bungarus fasciatus. Toxicon 2015, 107, 197-209. [CrossRef] 
35. Chapeaurouge, A.; Silva, A.; Carvalho, P.; McCleary, R.J.R.; Modahl, C.M.; Perales, J.; Kini, R.M.; Mackessy, S.P. Proteomic Deep Mining the Venom of the Red-Headed Krait, Bungarus flaviceps. Toxins 2018, 10, 373. [CrossRef] [PubMed]

36. Ahmed, M.; Latif, N.; Khan, R.A.; Ahmad, A.; Rocha, J.B.; Mazzanti, C.M.; Bagatini, M.D.; Morsch, V.M.; Schetinger, M.R. Enzymatic and biochemical characterization of Bungarus sindanus snake venom acetylcholinesterase. J. Venom. Anim. Toxins Incl. Trop. Dis. 2012, 18, 236-243. [CrossRef]

37. Cousin, X.; Créminon, C.; Grassi, J.; Méflah, K.; Cornu, G.; Saliou, B.; Bon, S.; Massoulié, J.; Bon, C. Acetylcholinesterase from Bungarus venom: A monomeric species. FEBS Lett. 1996, 387, 196-200. [CrossRef]

38. Daltry, J.C.; Wuster, W.; Thorpe, R.S. Diet and snake venom evolution. Nature 1996, 379, 537-540. [CrossRef] [PubMed]

39. Casewell, N.R.; Jackson, T.N.W.; Laustsen, A.H.; Sunagar, K. Causes and Consequences of Snake Venom Variation. Trends Pharmacol. Sci. 2020, 41, 570-581. [CrossRef]

40. Holding, M.L.; Biardi, J.E.; Gibbs, H.L. Coevolution of venom function and venom resistance in a rattlesnake predator and its squirrel prey. Proc. Biol. Sci. 2016, 283, 20152841. [CrossRef]

41. Rokyta, D.R.; Margres, M.J.; Ward, M.J.; Sanchez, E.E. The genetics of venom ontogeny in the eastern diamondback rattlesnake (Crotalus adamanteus). Peer] 2017, 5, e3249. [CrossRef]

42. Sunagar, K.; Undheim, E.A.; Scheib, H.; Gren, E.C.; Cochran, C.; Person, C.E.; Koludarov, I.; Kelln, W.; Hayes, W.K.; King, G.F.; et al. Intraspecific venom variation in the medically significant Southern Pacific Rattlesnake (Crotalus oreganus helleri): Biodiscovery, clinical and evolutionary implications. J. Proteom. 2014, 99, 68-83. [CrossRef]

43. Chanda, A.; Kalita, B.; Patra, A.; Senevirathne, W.; Mukherjee, A.K. Proteomic analysis and antivenomics study of Western India Naja naja venom: Correlation between venom composition and clinical manifestations of cobra bite in this region. Expert Rev. Proteom. 2019, 16, 171-184. [CrossRef]

44. Chanda, A.; Mukherjee, A.K. Quantitative proteomics to reveal the composition of Southern India spectacled cobra (Naja naja) venom and its immunological cross-reactivity towards commercial antivenom. Int. J. Biol. Macromol. 2020, 160, $224-232$. [CrossRef]

45. Chanda, A.; Patra, A.; Kalita, B.; Mukherjee, A.K. Proteomics analysis to compare the venom composition between Naja naja and Naja kaouthia from the same geographical location of eastern India: Correlation with pathophysiology of envenomation and immunological cross-reactivity towards commercial polyantivenom. Expert Rev. Proteom. 2018, 15, 949-961.

46. Kalita, B.; Mackessy, S.P.; Mukherjee, A.K. Proteomic analysis reveals geographic variation in venom composition of Russell's Viper in the Indian subcontinent: Implications for clinical manifestations post-envenomation and antivenom treatment. Expert Rev. Proteom. 2018, 15, 837-849. [CrossRef] [PubMed]

47. Jayanthi, G.P.; Gowda, T.V. Geographical variation in India in the composition and lethal potency of Russell's viper (Vipera russelli) venom. Toxicon 1988, 26, 257-264. [CrossRef]

48. Prasad, N.B.; Uma, B.; Bhatt, S.K.; Gowda, V.T. Comparative characterisation of Russell's viper (Daboia/Vipera russelli) venoms from different regions of the Indian peninsula. Biochim. Biophys. Acta 1999, 1428, 121-136. [CrossRef]

49. Shashidharamurthy, R.; Jagadeesha, D.K.; Girish, K.S.; Kemparaju, K. Variations in biochemical and pharmacological properties of Indian cobra (Naja naja naja) venom due to geographical distribution. Mol. Cell. Biochem. 2002, 229, 93-101. [CrossRef]

50. Rowan, E.G. What does beta-bungarotoxin do at the neuromuscular junction? Toxicon 2001, 39, 107-118. [CrossRef]

51. Durban, J.; Perez, A.; Sanz, L.; Gomez, A.; Bonilla, F.; Rodriguez, S.; Chacón, D.; Sasa, M.; Angulo, Y.; Gutiérrez, J.M.; et al. Integrated "omics" profiling indicates that miRNAs are modulators of the ontogenetic venom composition shift in the Central American rattlesnake, Crotalus simus simus. BMC Genom. 2013, 14, 234. [CrossRef] [PubMed]

52. Bradford, M.M. A rapid and sensitive method for the quantitation of microgram quantities of protein utilizing the principle of protein-dye binding. Anal. Biochem. 1976, 72, 248-254. [CrossRef]

53. Burbrink, F.T.; Lawson, R.; Slowinski, J.B. Mitochondrial DNA phylogeography of the polytypic North American rat snake (Elaphe obsoleta): A critique of the subspecies concept. Evolution 2000, 54, 2107-2118. [CrossRef]

54. Forstner, M.R.; Davis, S.K.; Arevalo, E. Support for the hypothesis of anguimorph ancestry for the suborder Serpentes from phylogenetic analysis of mitochondrial DNA sequences. Mol. Phylogenet. Evol. 1995, 4, 93-102. [CrossRef]

55. Sievers, F.; Wilm, A.; Dineen, D.; Gibson, T.J.; Karplus, K.; Li, W.; Lopez, R.; McWilliam, H.; Remmert, M.; Söding, J.; et al. Fast, scalable generation of high-quality protein multiple sequence alignments using Clustal Omega. Mol. Syst. Biol. 2011, 7, 539. [CrossRef] [PubMed]

56. Guindon, S.; Dufayard, J.F.; Lefort, V.; Anisimova, M.; Hordijk, W.; Gascuel, O. New algorithms and methods to estimate maximum-likelihood phylogenies: Assessing the performance of PhyML 3.0. Syst. Biol. 2010, 59, 307-321. [CrossRef] [PubMed]

57. Lefort, V.; Longueville, J.E.; Gascuel, O. SMS: Smart Model Selection in PhyML. Mol. Biol. Evol. 2017, 34, 2422-2424. [CrossRef] [PubMed]

58. Ronquist, F.; Teslenko, M.; Van Der Mark, P.; Ayres, D.L.; Darling, A.; Höhna, S.; Larget, B.; Liu, L.; Suchard, M.A.; Huelsenbeck, J.P. MrBayes 3.2, efficient Bayesian phylogenetic inference and model choice across a large model space. Syst. Biol. 2012, 61, 539-542. [CrossRef] [PubMed]

59. Altekar, G.; Dwarkadas, S.; Huelsenbeck, J.P.; Ronquist, F. Parallel Metropolis coupled Markov chain Monte Carlo for Bayesian phylogenetic inference. Bioinformatics 2004, 20, 407-415. [CrossRef] [PubMed]

60. Tamura, K.; Nei, M.; Kumar, S. Prospects for inferring very large phylogenies by using the neighbor-joining method. Proc. Natl. Acad. Sci. USA 2004, 101, 11030-11035. [CrossRef] 
61. Kumar, S.; Stecher, G.; Li, M.; Knyaz, C.; Tamura, K. MEGA X: Molecular Evolutionary Genetics Analysis across Computing Platforms. Mol. Biol. Evol. 2018, 35, 1547-1549. [CrossRef]

62. Schneider, C.A.; Rasband, W.S.; Eliceiri, K.W. NIH Image to ImageJ: 25 years of image analysis. Nat. Methods. 2012, 9, 671-675. [CrossRef]

63. Perez-Riverol, Y.; Csordas, A.; Bai, J.; Bernal-Llinares, M.; Hewapathirana, S.; Kundu, D.J.; Inuganti, A.; Griss, J.; Mayer, G.; Eisenacher, M.; et al. The PRIDE database and related tools and resources in 2019: Improving support for quantification data. Nucleic Acids Res. 2019, 47, D442-D450. [CrossRef]

64. Bolger, A.M.; Lohse, M.; Usadel, B. Trimmomatic: A flexible trimmer for Illumina sequence data. Bioinformatics 2014, 30, 2114-2120. [CrossRef]

65. Andrews. FASTQC v0.11.9. FastQC: A Quality Control Tool for High Throughput Sequence Data. 2010. Available online: http:/ / www.bioinformatics.babraham.ac.uk/projects / fastqc (accessed on 14 November 2020).

66. Grabherr, M.G.; Haas, B.J.; Yassour, M.; Levin, J.Z.; Thompson, D.A.; Amit, I.; Adiconis, X.; Fan, L.; Raychowdhury, R.; Zeng, Q.; et al. Full-length transcriptome assembly from RNA-Seq data without a reference genome. Nat. Biotechnol. $2011,29,644-652$. [CrossRef] [PubMed]

67. Langmead, B.; Salzberg, S.L. Fast gapped-read alignment with Bowtie 2. Nat. Methods. 2012, 9, 357-359. [CrossRef] [PubMed]

68. Haas, B.J.; Papanicolaou, A.; Yassour, M.; Grabherr, M.; Blood, P.D.; Bowden, J.; Couger, M.B.; Eccles, D.; Li, B.; Lieber, M.; et al. De novo transcript sequence reconstruction from RNA-seq using the Trinity platform for reference generation and analysis. Nat. Protoc. 2013, 8, 1494-1512. [CrossRef] [PubMed]

69. Altschul, S.F.; Gish, W.; Miller, W.; Myers, E.W.; Lipman, D.J. Basic local alignment search tool. J. Mol. Biol. 1990, 215 , 403-410. [CrossRef]

70. Li, B.; Dewey, C.N. RSEM: Accurate transcript quantification from RNA-Seq data with or without a reference genome. BMC Bioinformatics 2011, 12, 323. [CrossRef] [PubMed]

71. Tarazona, S.; Furio-Tari, P.; Turra, D.; Pietro, A.D.; Nueda, M.J.; Ferrer, A.; Conesa, A. Data quality aware analysis of differential expression in RNA-seq with NOISeq R/Bioc package. Nucleic Acids Res. 2015, 43, e140. [CrossRef]

72. Tarazona, S.; Garcia-Alcalde, F.; Dopazo, J.; Ferrer, A.; Conesa, A. Differential expression in RNA-seq: A matter of depth. Genome Res. 2011, 21, 2213-2223. [CrossRef]

73. Maisano, M.; Trapani, M.R.; Parrino, V.; Parisi, M.G.; Cappello, T.; D’Agata, A.; Benenati, G.; Natalotto, A.; Mauceri, A.; Cammarata, M. Haemolytic activity and characterization of nematocyst venom from Pelagia noctiluca (Cnidaria: Scyphozoa). Ital. J. Zool. 2013, 80, 168-176. [CrossRef]

74. Casewell, N.R.; Cook, D.A.; Wagstaff, S.C.; Nasidi, A.; Durfa, N.; Wuster, W.; Harrison, R.A. Pre-clinical assays predict pan-African Echis viper efficacy for a species-specific antivenom. PLoS Negl. Trop. Dis. 2010, 4, e851. [CrossRef]

75. World Health Organisation. World Health Organisation Guidelines for the Production, Control and Regulation of Snake Antivenom Immunoglobulins; World Health Organisation: Geneva, Switzerland, 2018.

76. Finey, D. Probit Analysis, 3rd ed.; Cambridge University Press: London, UK, 1971.

77. Mendonca-da-Silva, I.; Magela Tavares, A.; Sachett, J.; Sardinha, J.F.; Zaparolli, L.; Gomes Santos, M.F.; Lacerda, M.; Monteiro, W.M. Safety and efficacy of a freeze-dried trivalent antivenom for snakebites in the Brazilian Amazon: An open randomized controlled phase IIb clinical trial. PLoS Negl. Trop. Dis. 2017, 11, e0006068. [CrossRef]

78. Ainsworth, S.; Menzies, S.K.; Casewell, N.R.; Harrison, R.A. An analysis of preclinical efficacy testing of antivenoms for subSaharan Africa: Inadequate independent scrutiny and poor-quality reporting are barriers to improving snakebite treatment and management. PLoS Negl. Trop. Dis. 2020, 14, e0008579. [CrossRef] [PubMed] 